\title{
CO Induced Aggregation and Segregation of Highly Dilute Alloys: A Density Functional Theory Study
}

\author{
Konstantinos G. Papanikolaou, Matthew T. Darby and Michail Stamatakis* \\ Department of Chemical Engineering, University College London, Roberts Building, Torrington Place, \\ London WC1E 7JE, United Kingdom
}

\begin{abstract}
Highly dilute binary alloys composed of an active platinum group metal (PGM) and a more inert coinage metal are important in the field of catalysis, as they function as active and selective catalysts. Their catalytic properties depend on the surface "ensemble" of PGM atoms, whose size may be altered under reactive conditions. We use density functional theory and investigate the interaction of $\mathrm{CO}$, a molecule common in numerous industrially important chemistries, with alloys that are composed of a PGM (Pt, Pd, Rh, Ir, Ni) doped in coinage metal hosts $(\mathrm{Cu}, \mathrm{Au}, \mathrm{Ag})$. We study the adsorption of $\mathrm{CO}$ on the (211) step and (100) facet and compare our results to those previously obtained on the (111) facet. We determine strong correlations between the adsorption energies of $\mathrm{CO}$ across the facets and highlight the corresponding thermochemical scaling relations. Finally, we study the stability of isolated surface dopant atoms with respect to aggregation into clusters and segregation into the bulk, both in the presence and absence of CO. We find that strong COdopant interactions significantly influence the morphology of the catalyst surface, suggesting that it may be possible to establish control over the ensemble size of the dopant by tuning PCO.
\end{abstract}

*Corresponding Author. e-mail: $\underline{\text { m.stamatakis@ucl.ac.uk }}$ 


\section{Introduction}

Bimetallic catalysts often exhibit superior catalytic performance as compared to their monometallic counterparts. ${ }^{1}$ As a consequence these catalysts have been the subject of extensive research, ${ }^{2-6}$ being at the same time the workhorse of important large-scale applications, such as naphtha cracking, hydrotreating of crude oil, acrylonitrile synthesis, ammonia oxidation and the reduction of pollutants produced by diesel engines. ${ }^{7,8}$

A new class of bimetallic catalysts, that has recently drawn a lot of attention, is single atom alloys (SAAs). ${ }^{9,10}$ These catalysts are composed of isolated platinum group metal (PGM) atoms (i.e. Ni, Pt, Ir, Rh and $\mathrm{Pd}$ ) that reside on the surface layer of a coinage metal host (i.e. $\mathrm{Au}, \mathrm{Cu}, \mathrm{Ag}$ ). In such a configuration, chemical reactions (e.g. $\mathrm{H}_{2}$ dissociation) are activated on the highly active PGM dopant atom, and after spillover the catalysis occurs on the relatively inert coinage metal. ${ }^{10}$ This has been verified by density functional theory (DFT) as well as surface science studies. ${ }^{10-12}$ In addition SAAs exhibit superior activity compared to their monometallic hosts ${ }^{13}$ in conjunction with exceptional selectivity unrivalled by pure PGMs. Moreover, they show high resistance to $\mathrm{CO}$ poisoning, ${ }^{14}$ and have successfully catalysed reactions of practical interest, including hydrogenations, ${ }^{15}$ dehydrogenations, ${ }^{16} \mathrm{C}-\mathrm{H}$ activation, ${ }^{17}$ hydrosilylations ${ }^{18}$ and hydrogenolysis. ${ }^{19}$

Though SAAs are extremely promising new catalysts, their isolated single atoms are sometime unable to activate chemical bonds that can otherwise be broken by small ensembles of PGMs such as dimers, trimers and islands. ${ }^{20-22}$ Therefore in these cases the formation of surface aggregates in highly dilute alloy surfaces may be necessary in order to achieve reasonable catalytic rates. ${ }^{23}$ For example, Goodman and co-workers ${ }^{20}$ studied the catalytic oxidation of $\mathrm{CO}$ over a $\mathrm{Pd} / \mathrm{Au}$ bimetallic catalyst, and showed that isolated $\mathrm{Pd}$ sites could not dissociate $\mathrm{O}_{2}$ in the temperature range of $400-700 \mathrm{~K}$ and at $\mathrm{P}_{\mathrm{CO}}=1 \times 10^{-7}$ Torr. Importantly, at this low pressure, the formation of Pd islands was excluded..$^{21}$ Higher catalytic rates were obtained at higher PCO, as a result of the formation of Pd-Pd dimers and contiguous Pd atoms. In contrast, isolated Pd sites of the same alloy were found to be able to dissociate $\mathrm{H}_{2}$ at $85 \mathrm{~K} .{ }^{22}$ Furthermore, Sykes and co-workers reported $\mathrm{H}$ spillover from $\mathrm{Pd}$ sites to $\mathrm{Au}$ after co-adsorption of $\mathrm{CO}$ on the $\mathrm{Pd} / \mathrm{Au}(111)$ surface; the former was not possible in the absence of $\mathrm{CO}{ }^{12}$

These findings clearly demonstrate that the most desirable structure of a highly dilute alloy surface depends on the application we are interested in. It is established that the adsorption behaviour on alloy catalysts is rationalised through the so-called ensemble and ligand effects. ${ }^{24-26}$ These effects are related to the composition and electronic structure of the active site, respectively, and determine, to a large extent, the nature of the active site. It then follows that if one could possibly find a way to engineer the architecture of the surface of highly dilute alloys, one would be able to optimise their catalytic performance according to the needs of any particular application. Interestingly studies have shown that this may be achieved by pre-treating the catalytic surface under reactive conditions, thereby exploiting adsorbate-induced effects. ${ }^{27,28}$ Exposure of the surface to gas appears to considerably affect the structure of the catalytic surface, influencing surface 
segregation and aggregation. ${ }^{21,29,30}$ In consequence, adsorbate-induced structural changes have been the main focus of numerous theoretical and experimental studies, which have explored the effect of alloy surface exposure to number of gases (e.g. $\mathrm{CO}, \mathrm{H}_{2}, \mathrm{NO}$ and $\mathrm{O}_{2}$ ) in the aim of improving the catalytic properties of the material. $^{6,28,31-34}$

$\mathrm{CO}$ is typically used as a probe molecule for specifying the properties of adsorption on solid materials ${ }^{32,35}$ and it is known for inducing morphological changes to the catalytic surface when adsorbed thereon. For example, highly mobile carbonyl species on Pt- and Pd-doped $\mathrm{Fe}_{3} \mathrm{O}_{4}(001)$ are observed with scanning tunnelling microscopy (STM) after exposure of the surfaces to CO gas at low $\mathrm{P}_{\mathrm{CO}}$ (e.g. $2 \times 10^{-10}$ mbar); ${ }^{36,37}$ these species promote the formation of $\mathrm{Pd}$ and $\mathrm{Pt}$ aggregates over dopant dispersion. The possibility of COinduced surface manipulation has been demonstrated through experimental diffuse reflectance infrared Fourier transform spectroscopy (DRIFTS) and Fourier-transform infrared (FTIR) spectroscopy studies on highly dilute $\mathrm{Pd}-\mathrm{Au}^{38}$ and $\mathrm{Pd}-\mathrm{Cu}^{32}$ alloys. Both studies indicated that exposure of the alloy surfaces to $\mathrm{CO}$ gas caused the migration of Pd atoms from the bulk to the surface and the formation of dopant aggregates. The latter was evidenced by bands observed at relatively low wavenumbers of the FTIR spectra (ca. $2002 \mathrm{~cm}^{-1}$ - see Ref. 32) that correspond to $\mathrm{CO}$ adsorption on Pd atom clusters. These effects have been further investigated in other experimental $^{39}$ and DFT studies. ${ }^{28,33}$

In this work, we use periodic DFT to investigate the effect of CO on the structure of highly dilute alloys. We examine the most stable structures of PGM alloys in Ag, $\mathrm{Au}$ and $\mathrm{Cu}$ hosts. This study expands our previous work, which focused on the close-packed (111) facet, ${ }^{33}$ to other sites that are expected to be exposed in catalytic nanoparticles (NPs) and are highly important for catalysis. Thus, we focus on a (211) step, which models NP edge sites, as well as the (100) facet. We begin by studying the adsorption of CO on fifteen SAA surfaces. Then, we vary the dopant atom loading and CO coverage and investigate the propensity of the dopant to migrate from the bulk to the surface (segregation) in numerous highly dilute alloys (Pt, $\mathrm{Pd}, \mathrm{Rh}, \mathrm{Ir}$ and $\mathrm{Ni}$ doped in $\mathrm{Au}, \mathrm{Ag}$ and $\mathrm{Cu}$ hosts) in the presence and absence of $\mathrm{CO}$. We further study the propensity of surface dopant atoms to aggregate, focusing our analysis on SAA, dimer and trimer, configurations which are expected to occur at low dopant loadings (i.e. less than $5 \%$ ).

The rest of the paper is organised as follows: in Sect. 2 we present the setup of our DFT calculations, along with the equations used to calculate the adsorption, aggregation and segregation energies. In Sect. 3 we proceed by exploring the adsorption of $\mathrm{CO}$ on various highly dilute binary alloys including SAAs, dimers and trimers. In the same section, we also discuss the surface segregation and aggregation of PGM dopant atoms, and we show how these may be manipulated with the use of CO. Finally, we summarise our findings and underline the significance of our work in Sect. 4.

\section{Computational Methods}

\subsection{Density Functional Theory Setup}

DFT calculations were performed using the Vienna $a b$ initio Simulation Package (VASP) version 5.4.1..$^{40,41}$ The valence electrons were treated explicitly and the core ionic potentials were modelled using the 
projector augmented wave (PAW) method. ${ }^{42}$ A plane-wave basis set was employed and the kinetic energy cutoff was set to $400 \mathrm{eV}$. Calculations were performed under the generalised gradient approximation using the revised Perdew-Burke-Ernzerhof (RPBE) exchange-correlation functional. ${ }^{43}$ This functional has been specifically designed to improve upon over-binding issues, particularly tailored to the chemisorption of $\mathrm{CO} .{ }^{44}$ Moreover, binding energies calculated with RPBE have already been shown to be in excellent agreement to those experimentally acquired on SAA surfaces. ${ }^{33}$ Under-coordinated (211) edges were modelled using a fourlayer $(3 \times 1)$ slab where the two bottom-most layers are fixed at the corresponding RPBE lattice constant and the remaining ones are allowed to fully relax. The low-index (100) facet was modelled by a five-layer $(3 \times 3)$ slab, where the two bottom-most layers were fixed and others were allowed to fully relax. Periodic images in the z-direction were separated by a $10 \AA$ vacuum in both cases and the first Brillouin zones of the (211) step and (100) facets were sampled with a $6 \times 5 \times 1$ and a $7 \times 7 \times 1$ Monkhorst-Pack k-point mesh, respectively. The k-point sampling schemes were chosen after converging the adsorption energy of $\mathrm{CO}$ with respect to the k-point mesh (see Supplementary Material). In all cases, we used the RPBE-calculated equilibrium lattice constants of the coinage metal host (3.64 $\AA, 4.23 \AA$ and $4.22 \AA$ for $\mathrm{Cu}, \mathrm{Ag}$ and $\mathrm{Au}$, respectively). Finally, we assured electronic self-consistency up to a tolerance of $10^{-7} \mathrm{eV}$ and the Hellmann-Feynman forces acting on all ions that are free to move were relaxed to less than $10^{-2} \mathrm{eV} / \AA$. The adsorption energy of $m$ CO molecules $\left(E_{a d s}(m C O)\right)$ was computed according to Eq. (1):

$E_{\text {ads }}(m C O)=E_{\text {tot }}^{m C O+s l a b}-E_{\text {tot }}^{s l a b}-m E_{\text {tot }}^{C O_{(g)}}$,

where $E_{t o t}^{m C O+s l a b}$ is the DFT total energy of $m C O$ molecules co-adsorbed on a slab, $E_{t o t}^{s l a b}$ is the DFT total energy of the clean slab and $E_{t o t}^{C O_{(g)}}$ the DFT total energy of a CO molecule in the gas phase. We note that more negative values of $\mathrm{E}_{\mathrm{ads}}(\mathrm{CO})$ indicate stronger $\mathrm{CO}$ binding on the surface.

The segregation energy $\left(\Delta E_{s e g}\right)$, denoting the enthalpic preference for a dopant atom to reside in the bulk versus in the surface layer of the host material, is given by Eq. (2):

$\Delta E_{\text {seg }}=E_{\text {tot }, \text { Bulk }}-E_{\text {tot }, \text { SAA }}$,

where $E_{t o t, B u l k}$ is the DFT total energy of the dopant atom immersed in the $3^{\text {rd }}$ layer of the slab (Figure 1) and $E_{t o t, S A A}$ is the DFT total energy of the clean slab with the dopant atom in the surface layer (Figure 1). Negative values of $\Delta E_{\text {seg }}$ imply a preference of the dopant to segregate into the bulk, whereas positive values indicate preference for segregation to the surface layer.

The CO-induced segregation energy $\Delta E_{\text {seg }}^{C O}$ (see supplementary information of Ref. 33) is given by Eq.

$\Delta E_{\text {seg }}^{C O}=\Delta E_{\text {seg }}+\left\{E_{\text {ads }}^{\text {host }}(C O)-E_{a d s}^{S A A}(C O)\right\}$, 
where $E_{a d s}^{\text {host }}(C O)$ and $E_{a d s}^{S A A}(C O)$ are the adsorption energies of one $\mathrm{CO}$ molecule on the pure host material and SAA, respectively.

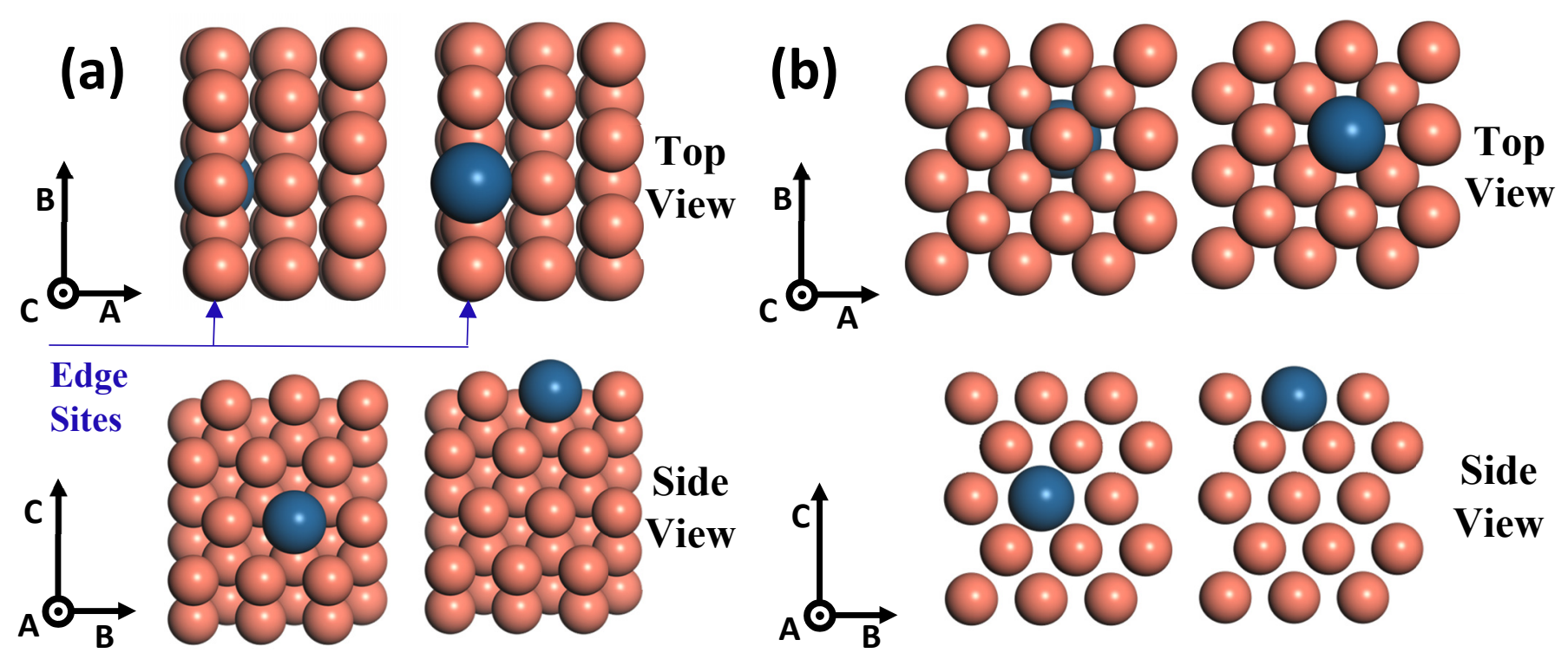

Figure 1. (a) Figures in the first row show the top view of the (211) slab with the dopant atom (blue) being immersed in the $3^{\text {rd }}$ layer of the host matrix (orange)-(top-left figure) and then being placed on the top layer (top-right figure). Figures in the second row show the side view of the same slabs. (b) Figures in the first row show the top view of the (100) slab with the dopant atom (blue) being immersed in the $3^{\text {rd }}$ layer of the host matrix (orange)-(top-left inset) and then being placed on the top layer (top-right inset). Figures in the second row show the side view of the same slabs. In the schematics of the axes the symbol $\mathbf{O}$ denotes an arrow pointing from the page towards the reader.

The aggregation energy $\left(\Delta E_{\text {agg }}\right)$, denoting the thermodynamic preference for the formation of clusters (dimers and trimers) from isolated dopant atoms, is given by Eq. (4):

$\Delta E_{\text {agg }}=E_{\text {tot }}(n)+(n-1) \cdot E_{t o t}($ host $)-n \cdot E_{\text {tot }}(S A A)$,

where $E_{t o t}(n), E_{t o t}(h o s t)$ and $E_{\text {tot }}(S A A)$ are the DFT total energies of an alloy with a cluster of $n$ dopant atoms, the pure host material and the SAA, respectively. According to Eq. (4), $\Delta E_{a g g}<0$ indicates a preference for the dopant atoms to cluster on the surface. Conversely, $\Delta E_{a g g}>0$ implies a thermodynamic preference for the SAA phase.

A CO molecule can induce aggregation if its adsorption energy on an n-mer dopant island $\left(E_{a d s}^{n-m e r}(C O)\right)$ is more negative than on the SAA $\left(E_{a d s}^{S A A}(C O)\right)$, such that positive values of $\Delta E_{a g g}$ may be offset. ${ }^{33}$ It follows that the $\mathrm{CO}$-induced aggregation energy $\left(\Delta E_{a g g}^{m \times C O}(n)\right)$ is expressed as:

$\Delta E_{a g g}^{m \times C O}(n)=\Delta E_{a g g}(n)-\left\{m \cdot E_{a d s}^{S A A}(C O)-E_{a d s}^{n-m e r}(m C O)\right\}$,

where $\mathrm{m}$ represents the number of $\mathrm{CO}$ molecules adsorbed on the $n$-mer dopant island.

\section{Results and Discussion}

\subsection{CO Adsorption on SAA (211) and (100) Surfaces}

The active phase of a catalyst is often "organised" into NPs, which expose several facets connected to each other. The dominant facets on fcc metal NPs are the low index (111) and (100), which are linked by edge 
sites. ${ }^{45}$ In our previous work, we modelled the adsorption of CO to SAA and pure metal (111) surfaces. We now expand our investigations to the (211) and (100) facets, and in this way we examine the vast majority of sites being found on commonly encountered NP geometries (e.g. cube-octahedral and octahedral). To model under-coordinated edge sites we employ a (211) step, whereon sites with coordination number equal to 7 can be found. Edge sites exhibit distinct electronic environments as compared to lower index facets and are of great interest in catalysis because of their high reactivity. ${ }^{46,47}$ Although these sites are often highly active ${ }^{48,49}$ and can make notable contributions to the overall catalytic rate, they are also known for their susceptibility to poisoning (e.g. CO and sulfur poisoning). ${ }^{49}$ This is the result of their very strong interaction with certain adsorbates, which bind tightly to these sites leading to their deactivation. ${ }^{50}$

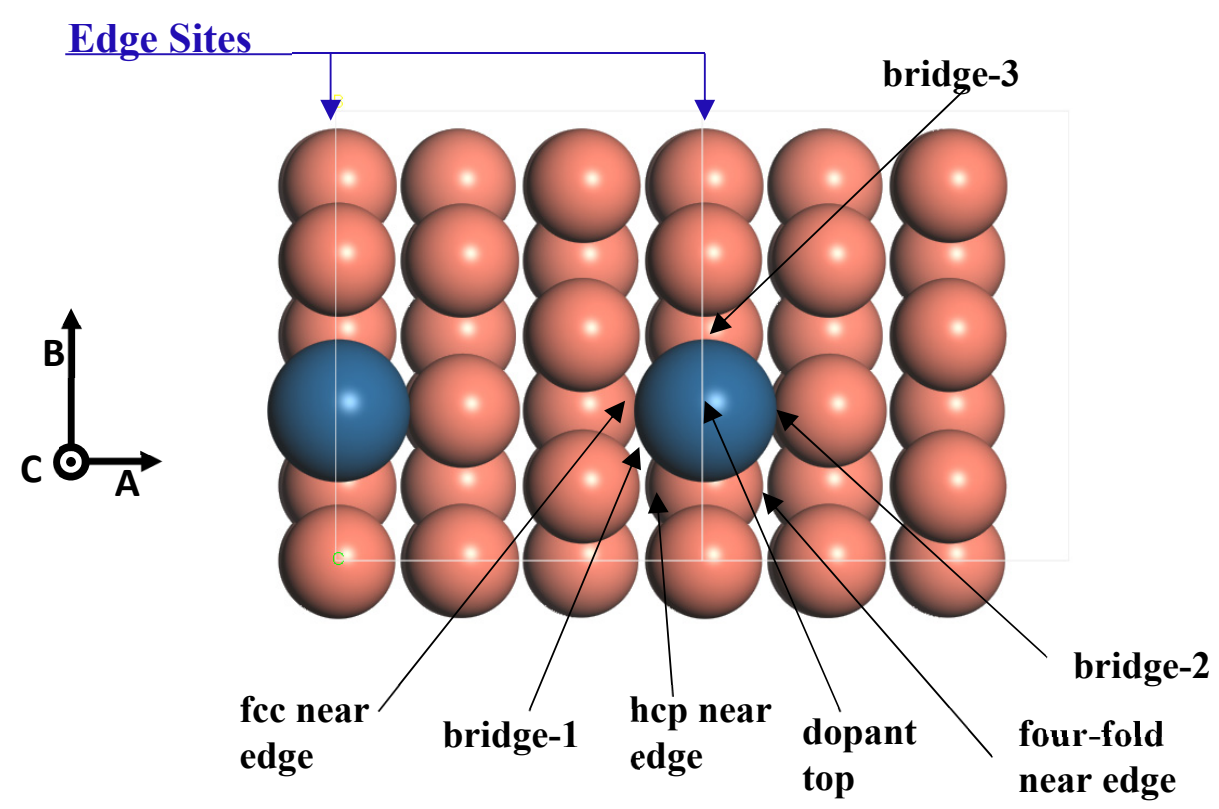

Figure 2. Top view of the (211) slab, showing the sites whereon CO can adsorb. This includes: three bridge sites (i.e. bridge-1, bridge-2 and bridge-3), a four-fold near edge site, two three-fold near edge sites (i.e. hcp near edge, fcc near edge) and the dopant (blue) top site. Host metal atoms shown in orange.

Using the RPBE xc-functional and the computational setup described in section 2.1 we study the adsorption of CO to (211) SAA surfaces and pure metal surfaces. Previous theoretical studies, which employed RPBE as the xc-functional (see Ref. 33), demonstrate excellent agreement between simulated and experimentally obtained temperature programmed desorption (TPD) data for various pure metal (111) and SAA (111) surfaces (including, $\mathrm{Pd} / \mathrm{Cu}(111), \mathrm{Pt} / \mathrm{Cu}(111), \mathrm{Pd} / \mathrm{Au}(111)$ and others), with a mean absolute error in the $\mathrm{CO}$ binding energy of $0.04 \mathrm{eV}$. One could employ a hybrid functional, ${ }^{51,52}$ or a DFT+U type method ${ }^{53,54}$ to further improve the reliability of our DFT calculations. Yet, the increased cost of such methods may not be necessary given the excellent performance of the RPBE functional for reproducing the experimental Eads $(C O) .33,44$ Herein, we present calculations for the adsorption energy of CO (Eads $(C O))$ on fifteen (211) SAA surfaces, including Pt-, Pd-, Rh-, Ir- and Ni-doped $\operatorname{Ag}(211), \operatorname{Au}(211)$ and $\mathrm{Cu}(211)$. Eads(CO), is computed on seven different adsorption sites, which are on or proximal to the edge of SAA and pure metal (211) surfaces (Figure 2). We determine that in all SAA (211) surfaces the most stable adsorption site is the top dopant site and the corresponding $\mathrm{E}_{\mathrm{ads}}(\mathrm{CO})$ values are plotted in Figure 3(a). In the same figure we also 
plot $\mathrm{E}_{\mathrm{ads}}(\mathrm{CO})$ on the most stable adsorption site of (211) pure metal surfaces (e.g. $\mathrm{Pt}(211), \operatorname{Pd}(211), \mathrm{Cu}(211)$ etc.), which can be either the edge top site or the edge bridge site (bridge-3 in Figure 2), depending on the metal.

We find $\mathrm{E}_{\text {ads }}(\mathrm{CO})=-0.70 \mathrm{eV}$ on $\mathrm{Cu}(211)$, which is in reasonable agreement with that estimated by experiment $($ Eads $(\mathrm{CO}) \approx-0.61 \pm 0.01 \mathrm{eV}) .{ }^{55}$ We also find that DFT is consistent with infrared reflection absorption (IRA) spectroscopy, ${ }^{56}$ predicting that adsorbed CO is considerably more stable on top sites over the $\operatorname{Ir}(211)$ surface $\left(\mathrm{E}_{\text {ads }}(\mathrm{CO})=-2.14 \mathrm{eV}\right)$. Furthermore, our results suggest that the most stable adsorption site on the $\mathrm{Rh}(211), \operatorname{Pd}(211), \operatorname{Pt}(211)$ and $\mathrm{Ni}(211)$ surfaces is the edge two-fold site (bridge-3 in Figure 2), whereon we find $\mathrm{E}_{\text {ads }}(\mathrm{CO})=-1.75 \mathrm{eV},-1.64 \mathrm{eV},-1.75 \mathrm{eV}$ and $-1.55 \mathrm{eV}$, respectively. Interestingly, the twofold edge site is marginally more stable than the top edge on $\operatorname{Pt}(211)$, where we calculate $\mathrm{E}_{\text {ads }}(\mathrm{CO})=-1.750$ $\mathrm{eV}$ and $-1.744 \mathrm{eV}$, respectively. This marginal difference of the $\mathrm{E}_{\mathrm{ads}}(\mathrm{CO})$ on these two sites is also reported in studies that combine theory and experiment. ${ }^{57}$ We also note that the CO adsorption strength is significantly lower on (211) coinage surfaces (i.e. $\mathrm{Cu}(211), \mathrm{Au}(211)$ and $\mathrm{Ag}(211)$ ) compared to that of the PGMs (i.e. $\operatorname{Pt}(211), \operatorname{Pd}(211), \operatorname{Rh}(211), \operatorname{Ni}(211)$ and $\operatorname{Ir}(211)$ ) (Figure 3(a)), testament to the much higher poisoning susceptibility of the latter over the former.
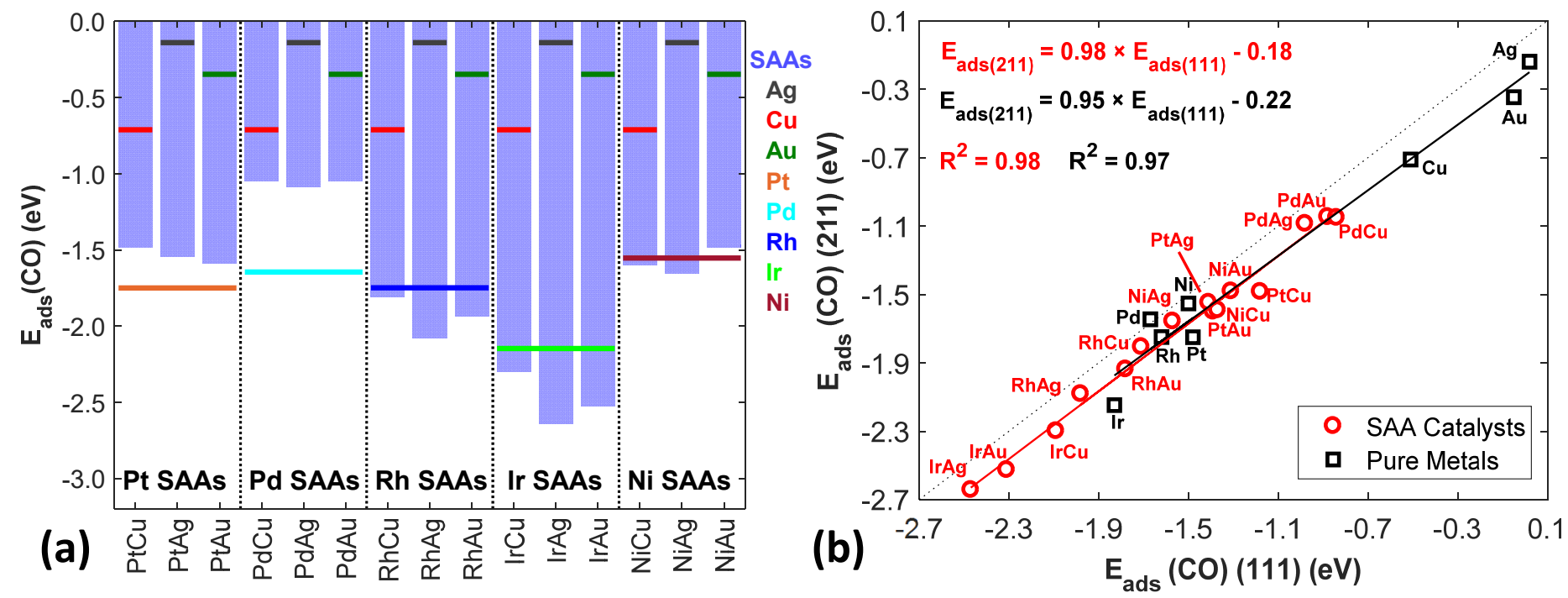

Figure 3. (a) The bars show adsorption energies of $\mathrm{CO}\left(\mathrm{E}_{\mathrm{ads}}(\mathrm{CO})\right)$ on the most stable sites of SAA (211) surfaces. $\mathrm{E}_{\mathrm{ads}}(\mathrm{CO})$ for (211) pure metal surfaces are shown by coloured lines [Ag (black), $\mathrm{Cu}$ (green), $\mathrm{Au}$ (red), $\mathrm{Pt}$ (orange), $\mathrm{Pd}$ (cyan), Rh (blue), Ir (light green) and $\mathrm{Ni}$ (burgundy)]. (b) Linear correlation between $\mathrm{E}_{\text {ads }}(\mathrm{CO})(211)$ and $\mathrm{E}_{\text {ads }}(\mathrm{CO})(111)$ for SAAs (red hollow circles) and pure metals (black hollow squares). Regression lines and equations are shown, with the corresponding coefficients of determination $\left(\mathrm{R}^{2}\right)$ and the parity line (dashed black line).

Some SAAs bind $\mathrm{CO}$ with an intermediate strength as compared to the coinage metals and PGMs. Interestingly however, the adsorption strength of $\mathrm{CO}$ on Ir and Rh SAAs is enhanced compared to pure $\operatorname{Rh}(211)$ and $\operatorname{Ir}(211)$. The calculated $E_{a d s}(\mathrm{CO})$ values on $\mathrm{Rh} / \mathrm{Ag}(211), \mathrm{Rh} / \mathrm{Au}(211), \operatorname{Ir} / \operatorname{Ag}(211)$ and $\operatorname{Ir} / \operatorname{Au}(211)$ are $-2.08 \mathrm{eV},-1.93 \mathrm{eV},-2.64 \mathrm{eV}$ and $-2.52 \mathrm{eV}$, respectively (compared to $-1.75 \mathrm{eV}$ and $-2.14 \mathrm{eV}$ on pure $\mathrm{Rh}(211)$ and $\operatorname{Ir}(211)$, respectively). This very strong dopant-CO interaction, particularly for $\mathrm{Ir} / \mathrm{Ag}$ and $\mathrm{Rh} / \mathrm{Ag}$, can be attributed to poor charge mixing between the dopant and host and gas like behaviour of the former, as evidenced by sharp features of the $d$-band density of states (DOS) that appear close to the Fermi level. ${ }^{58}$ 
On the other hand, the CO adsorption strength on Pt and $\mathrm{Pd}(211)$ SAA surfaces is significantly reduced compared to that on pure $\operatorname{Pt}(211)$ and $\operatorname{Pd}(211)$. For example the binding strength of $\mathrm{CO}$ on $\mathrm{Pt} / \mathrm{Cu}(211)$ is weaker by ca. $0.27 \mathrm{eV}$ compared to $\mathrm{Pt}(211)$, while the corresponding reduction between $\mathrm{Pd} / \mathrm{Au}(211)$ and $\operatorname{Pd}(211)$ is about $0.60 \mathrm{eV}$. It follows that these two alloys will be more resistant to $\mathrm{CO}$ poisoning relative to the monometallic PGM edges. Indeed, $\mathrm{Pd} / \mathrm{Au}$ and $\mathrm{Pt} / \mathrm{Cu}$ SAAs have been shown to exhibit high resistance to $\mathrm{CO}$ poisoning, whilst performing highly selective hydrogenations. ${ }^{14,17,22}$ Our results suggest that $\mathrm{Pt} / \mathrm{Ag}, \mathrm{Pt} / \mathrm{Au}$, $\mathrm{Pd} / \mathrm{Cu}$ and $\mathrm{Pd} / \mathrm{Ag}$ SAAs also have the potential to exhibit high $\mathrm{CO}$ tolerance and a previous screening study has suggested that they are also of interest for use as hydrogenation catalysts, thanks to facile $\mathrm{H}_{2}$ activation and subsequent $\mathrm{H}$ spillover. ${ }^{59}$

Briefly comparing to our previous work on the (111) surface, ${ }^{33}$ we plot $E_{\text {ads }}(\mathrm{CO})(211)$ versus $\mathrm{E}_{\text {ads }}(\mathrm{CO})$ (111) in Figure 3(b) and make the general observation that the binding strength of CO on the (211) edge is consistently greater than that on the (111) facet for both the pure metal catalyst and SAAs. Importantly, there is a strong correlation between $\operatorname{Eads}_{(\mathrm{CO})}(211)$ and $\mathrm{Eads}_{\mathrm{a}}(\mathrm{CO})(111)$ (Figure 3(b)), with $\mathrm{CO}$ binding being systematically stronger on the (211) SAA surfaces by $0.18 \mathrm{eV}$ on average, compared to (111) SAA surfaces. The same is true for the pure metal catalysts examined, for which we find that the binding strength of $\mathrm{CO}$ on (211) is greater than that on (111) by approximately $0.2 \mathrm{eV}$. This result is in line with the surface (211) atoms having a lower coordination number than those on (111) ( 7 versus 9 , respectively).
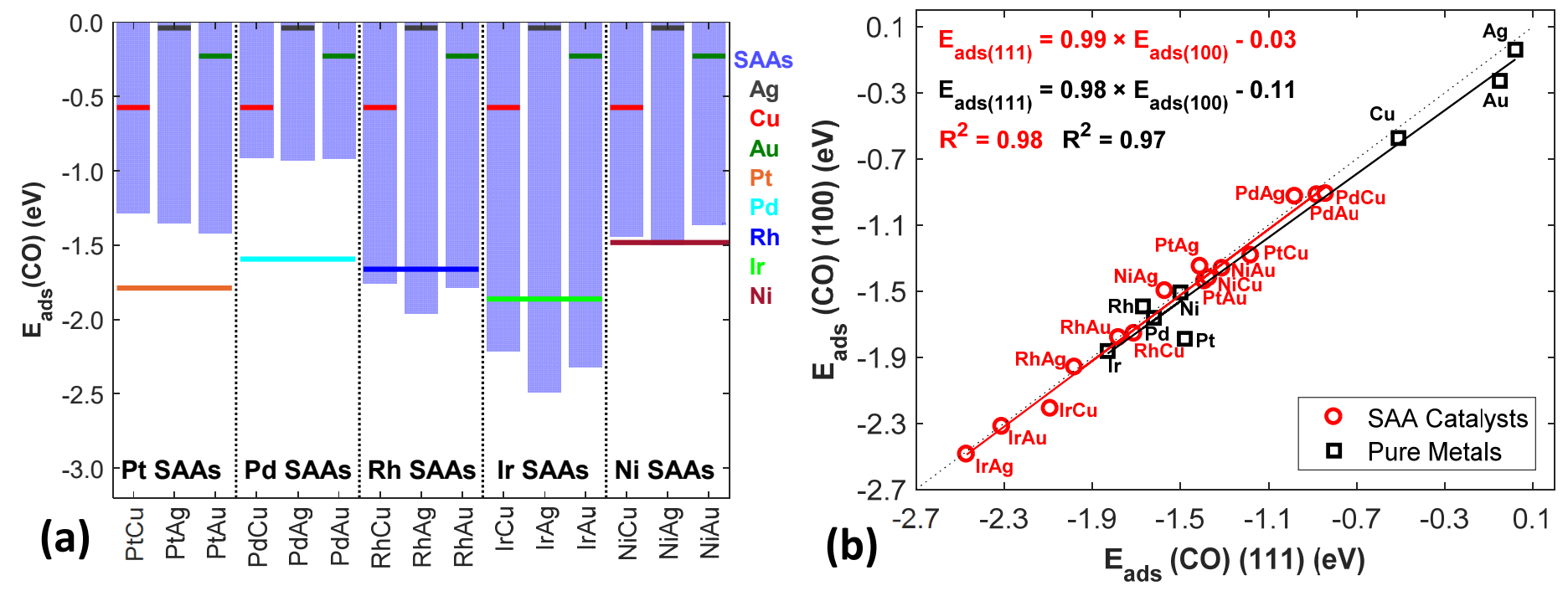

Figure 4. (a) The bars show adsorption energies of $\mathrm{CO}\left(\mathrm{E}_{\mathrm{ads}}(\mathrm{CO})\right)$ on the most stable sites of SAA (100) surfaces. $\mathrm{E}_{\mathrm{ads}}(\mathrm{CO})$ for pure (100) metals are shown by coloured lines [Ag (black), $\mathrm{Cu}$ (green), $\mathrm{Au}$ (red), Pt (orange), Pd (cyan), $\mathrm{Rh}$ (blue), Ir (light green) and $\mathrm{Ni}$ (Burgundy)]. (b) Linear correlation between $\mathrm{E}_{\text {ads }}(\mathrm{CO})(100)$ and $\mathrm{E}_{\text {ads }}(\mathrm{CO})$ (111) for SAAs (red) and pure metals (black). Regression lines and equations are shown, with the corresponding coefficients of determination $\left(\mathrm{R}^{2}\right)$ and the parity line (dashed black line).

In a similar manner to our study on the (211) edge, we consider the adsorption behaviour of $\mathrm{CO}$ on (100) SAA and pure metal surfaces, whereon surface atoms have a coordination number of 8 . We plot DFT calculated $E_{a d s}(C O)$ on (100) SAA and pure metal surfaces in Figure 4(a) and we find that our computed values of $\mathrm{E}_{\mathrm{ads}}(\mathrm{CO})$ on $\mathrm{Cu}(100)$ and $\mathrm{Ni}(100)$ are in agreement with other DFT using RPBE and experimental studies. ${ }^{60,61}$ 
Interestingly, trends of the $\mathrm{CO}$ adsorption energy are similar to those observed on the (211) edges, though binding of $\mathrm{CO}$ on the (100) facet is in general weaker (Figure 4(a)). As with the (211) edges, CO binds very strongly on Ir and Rh (100) SAAs, whereon the adsorption is more exothermic than on pure Ir and Rh (100) surfaces. This trend holds on (211), (100) and (111), ${ }^{33}$ and it follows that Ir and Rh SAA nanoparticles will be more susceptible to $\mathrm{CO}$ poisoning, and therefore inappropriate for applications that require high $\mathrm{CO}$ poisoning resistance (e.g. steam reforming). ${ }^{62}$ However, using the $\mathrm{CO}$ binding strength as an indicator/descriptor of reactivity, Rh and Ir SAAs are likely to be promising catalysts for breaking strong chemical bonds that cannot be activated by other SAAs. ${ }^{20}$ Indeed, previous calculations have shown that Rh SAAs in general exhibit some of the lowest activation barriers for numerous reactions (e.g. C-H activation and $\mathrm{N}-\mathrm{H}$ scission) in screening study of SAA reactivity. ${ }^{59}$

As with adsorption on the (211) edge, Eads $(C O)$ (100) is strongly correlated with Eads(CO) (111) (Figure 4(b)) for both SAA and pure metal surfaces. In particular, for pure metals we find the relative binding strength across the different surfaces to decrease as follows: $(211)>(100)>(111)$, which, according to our results suggests that an increase in the coordination number by 1 corresponds to ca. $0.1 \mathrm{eV}$ decrease in the binding strength. This trend is in line with the findings of a previous work on various Pt and Au surfaces, ${ }^{63}$ and also in agreement with the $d$-band center model of Hammer and Nørskov. ${ }^{64}$ The latter suggests broadening of the $d$-band upon increasing coordination number and therefore weaker binding. ${ }^{6}$

On the other hand, despite the different coordination numbers of the surface atoms on SAA (100) and (111) facets, the adsorption energies calculated thereon are very similar (i.e. Eads $(C O)(100) \approx \mathrm{Eads}_{(\mathrm{CO})}(111)$ ), as most of the SAA data points lie on the parity line (Figure 4(b), red). We postulate that the similarities in CO adsorption behaviour of SAA (111) and (100) surfaces is the result of a lack of charge mixing between the dopant atom and the coinage metal atoms, which makes the former behave more like an isolated site rather than part of a well-delocalised surface state. ${ }^{58}$ Consequently, the available electron densities for adsorbate binding are similar for dopant atoms in both facets and hence is the $\mathrm{CO}$ binding strength. ${ }^{58}$ If indeed the $\mathrm{CO}$ adsorption strength is a metric for reactivity, it is suggestive that the adsorption energy of other adspecies on the (100) and (111) SAA facets will be comparable, and that structure sensitive reactions may be preferred on one facet over the other. Thus, we attribute the variation between the (211) edge and the flat surfaces to the notable differences in the surface geometry ${ }^{66}$ rather than alloy constitution. The binding strength of $\mathrm{CO}$ on the SAA surfaces follows the order $(211)>(100) \approx(111)$.

\subsection{CO adsorption on dopant atom dimers}

In addition to SAA surfaces, we studied the adsorption of $\mathrm{CO}$ on dopant dimer configurations on the (100) and (211) surfaces and we compare the results to our previous work on the (111) facet ${ }^{33}$ (Figure 5). We briefly note that we do not consider results for dimers on $\mathrm{Ni} / \mathrm{Au}$ and $\mathrm{Ir} / \mathrm{Au}$ alloys as during ionic relaxation the DFT slab underwent significant reconstruction for these materials. 
We report $\mathrm{E}_{\mathrm{ads}}(\mathrm{CO})$ on the most favourable adsorption site for each alloy combination. We considered two site types: a dopant top site and a two-fold site bridging a dopant atom pair (Figure 5). In our previous work we found that $\mathrm{CO}$ generally prefers the two-fold bridge site on the (111) dopant dimer configurations, though exceptions to this are $\mathrm{Ir} / \mathrm{Ag}(111), \mathrm{Ir} / \mathrm{Cu}(111)$ and $\mathrm{Pt} / \mathrm{Cu}(111)$ dimers, where $\mathrm{CO}$ adsorption is most favourable on the top dopant site. ${ }^{33}$ Considering dimers on the (211) edge and the (100) facet, we determine that CO adsorption is most favoured on the dopant top site on $\operatorname{Ir} / \mathrm{Ag}(211), \operatorname{Ir} / \mathrm{Ag}(100), \operatorname{Ir} / \mathrm{Cu}(211)$ and $\operatorname{Ir} / \mathrm{Cu}(100)$, whereas in all other cases the two-fold bridge site between the two adjacent dopant atoms is preferred.
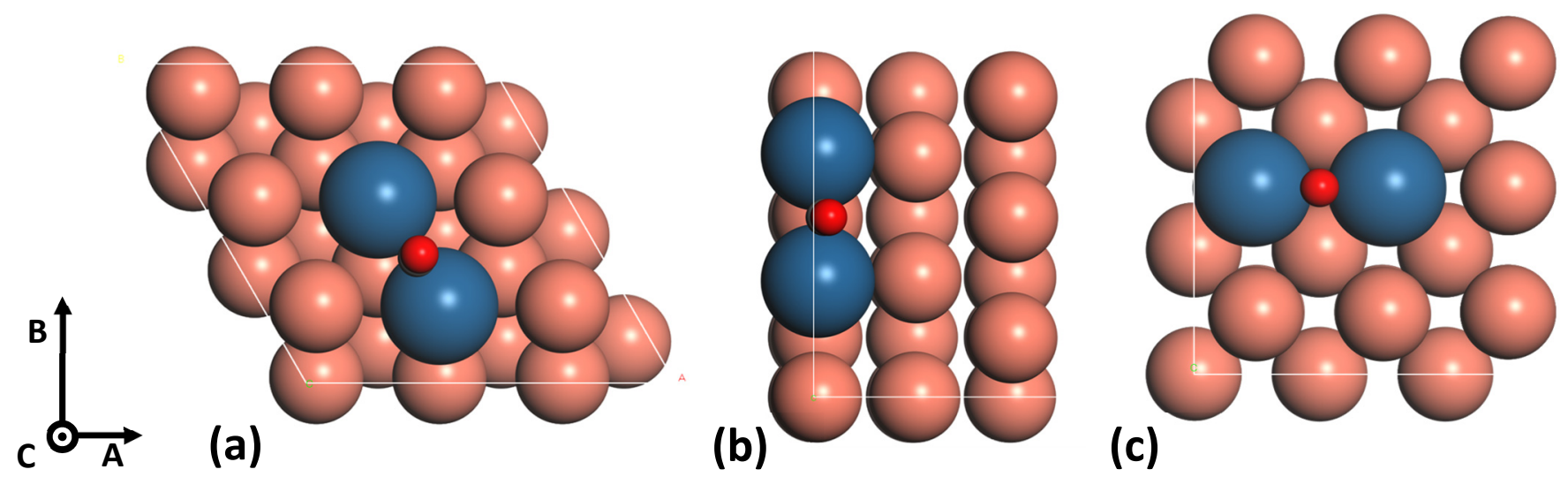

Figure 5. Panels (a), (b) and (c) show the dopant dimers (blue) on a coinage metal (orange) on (111), (211) and (100) facets, respectively. In all panels there is a CO molecule adsorbed on the bridge site between the dopant atoms. Carbon and oxygen atoms are represented by grey and red spheres, respectively.

We plot the Eads $(\mathrm{CO})$ on (211) edge and (100) dimers versus those on the dimer of the (111) facet ${ }^{33}$ in Figure 6(a) and (b), respectively. We observe that there is a correlation between the adsorption energies on dimers of the different facets. Interestingly, we find that for all binary alloy combinations the adsorption strength on (111) dimers is significantly weaker as compared to that on (100) dimers (weaker on average by $0.23 \mathrm{eV}$ ). In fact, the relative binding stability ordering on dopant dimers is akin to that on the pure metals, namely $(211)>(100)>(111) .{ }^{63}$ Accordingly, Eads $(C O)$ scales with the coordination number in a similar manner as for pure metal catalysts (approximately $0.1 \mathrm{eV}$ per coordination number increase by 1). Finally, we highlight that the binding of CO is considerably stronger on (211) dimers than on (111) dimers (on average by $0.41 \mathrm{eV}$ ). This result implies that the formation of edge dimers will be contributing significantly to the high susceptibility of edges to $\mathrm{CO}$ poisoning. 

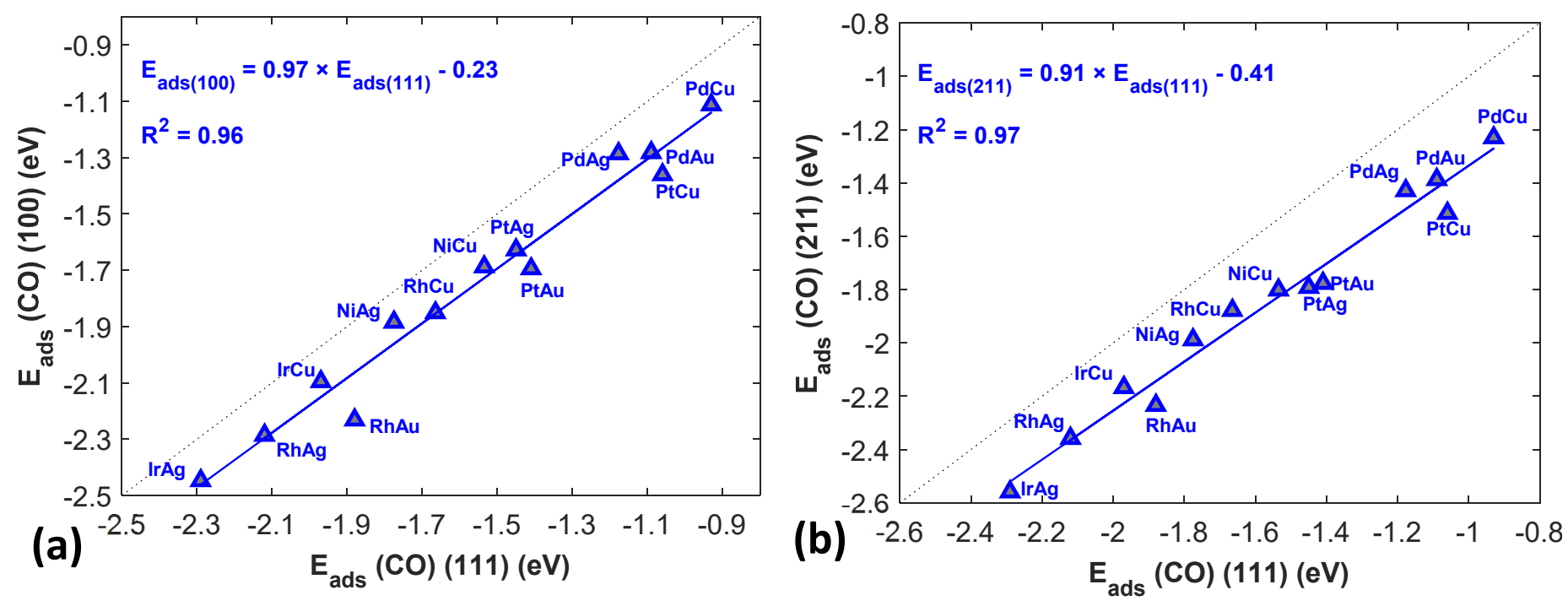

Figure 6. (a) Comparison of $E_{a d s}(C O)(100)$ and $E_{a d s}(C O)$ (111) calculated on the most stable adsorption site of dopant dimer configurations. (b) Comparison of $E_{a d s}(C O)(211)$ and $E_{a d s}(C O)(111)$ calculated on the most stable adsorption site of dopant dimer configurations. Regression lines and equations are shown, with the corresponding coefficients of determination $\left(\mathrm{R}^{2}\right)$ and a parity line (dashed black line).

\subsection{Surface segregation studies}

The enthalpic preference of a dopant atom to reside on the surface layer or in the bulk matrix of the host metal is quantified by the segregation energy, $\Delta E_{\text {seg. }}$. We compute $\Delta E_{\text {seg }}$ for fifteen binary alloys, always relative to the SAA phase. Based on Eq. (2), when $\Delta E_{s e g}>0$ there will be a thermodynamic preference for the dopant atom to segregate to the surface in favour of the SAA phase. On other hand, when $\Delta E_{s e g}<0$ there will be a preference of segregation into the bulk matrix of the coinage metal host such that the dopant atom is submerged therein. To compute these $\Delta E_{\text {seg }}$ values, we perform two calculations for each binary alloy on (100) and (211) facets: first, with one dopant atom in the top layer of the slab (Figure 1), forming a SAA and second, with the isolated dopant immersed in the bulk matrix of the coinage metal (Figure 1). We note that the results presented herein provide information on the thermodynamic stability of the different investigated structures, but neglect entropic and kinetic effects which are important under experimental conditions.

We calculate $\Delta E_{\text {seg }}$ for fifteen alloys with the (211) and (100) structures and present the results as a parity plot in Figure 7. In the absence of any adsorbates on the surface we find $\Delta E_{\text {seg }}<0$ for almost all the (211) and (100) binary alloys. Therefore, in the majority of cases, the dopant atom has a thermodynamic preference for segregation into the bulk of the coinage metal (Figure 7). Exceptions to this observation are $\mathrm{Pd} / \mathrm{Cu}(211)$ and $\mathrm{Pd} / \mathrm{Cu}(100)$, for which we calculate slightly positive values of $\Delta E_{\text {seg }}(0.07 \mathrm{eV}$ and $0.06 \mathrm{eV}$, respectively), and attribute this to the fact that $\mathrm{Pd}$ and $\mathrm{Cu}$ atoms have very similar surface energies on (211) and (100) surfaces. ${ }^{67}$ The trends in the segregation of dopant metal atoms in SAA (211) and (100) surfaces are very similar to those on the (111) facet. The only difference is Pt/Cu SAA, where $\Delta E_{\text {seg }}>0$ on (111), ${ }^{33}$ whereas we find $\Delta E_{\text {seg }}<0$ on (100) and (211). 


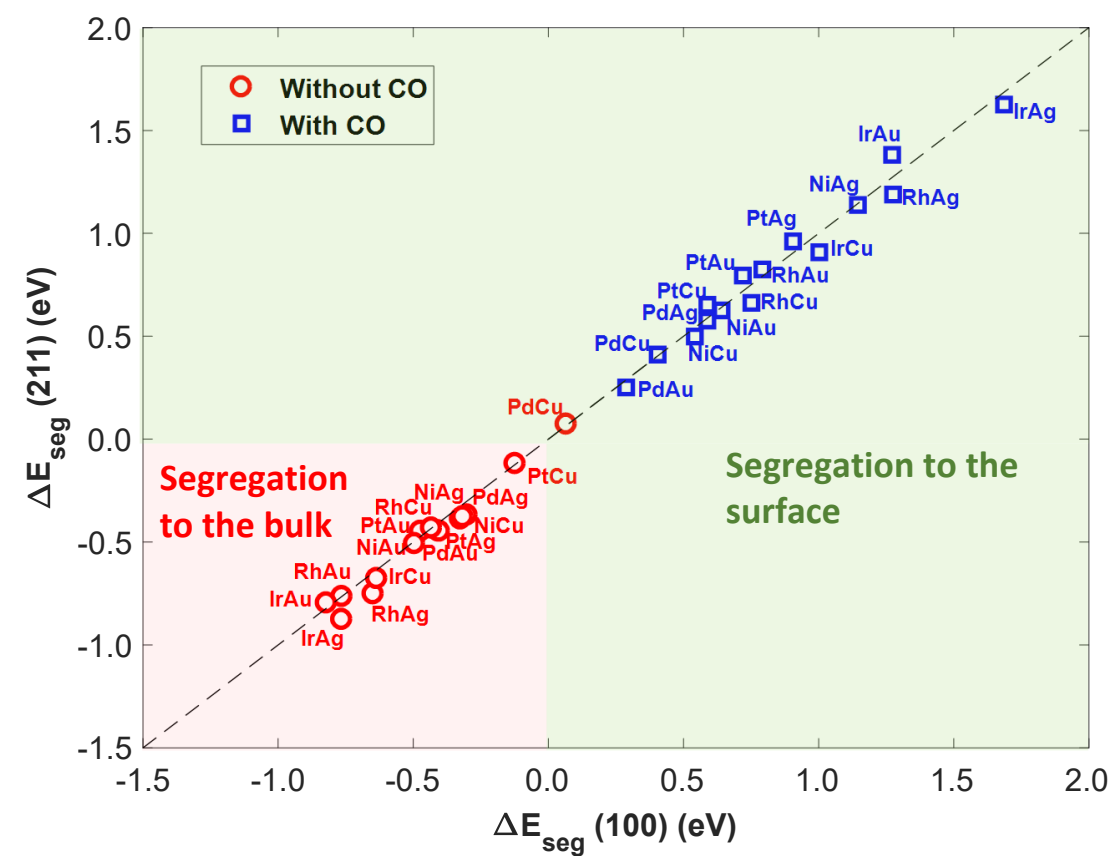

Figure 7. Calculated $\Delta E_{\text {seg }}$ for fifteen binary alloys in the absence of adsorbed $\mathrm{CO}$ (red hollow circles) and in the presence of adsorbed CO (black hollow squares). Segregation of the dopant atom to the surface is favoured in the area highlighted in green. The opposite is true in the area highlighted in red.

The thermodynamic preference for the dopant to submerge into the bulk matrix of the coinage metal may be reversed by the presence of a potent adsorbate (e.g. CO). ${ }^{27,28,32,34}$ Indeed, adsorbates that interact strongly with metal atoms usually enrich the surface of bimetallic catalysts with those metal atoms. ${ }^{68}$ Thus, we continue by considering the possibility of inducing segregation through $\mathrm{CO}$ adsorption. In the presence of an adsorbed $\mathrm{CO}$ molecule, we compute the CO-induced segregation energy $\Delta E_{\text {seg }}^{C O}$ (Eq. (3)) for each binary alloy. Our calculations suggest that the adsorption of $\mathrm{CO}$ will induce segregation of the dopant to the surface for every binary alloy as $\Delta E_{\text {seg }}^{C O}>0$ in both (211) and (100) surfaces (Figure 7). It follows that the relative adsorption strength of $\mathrm{CO}$ on the SAAs is sufficiently greater than on the pure coinage metals, overcoming any negative $\Delta E_{\text {seg }}$ and making $\Delta E_{\text {seg }}^{C O}$ always positive (see Eq. (3)).

Interestingly, we note that the most positive $\Delta E_{\text {seg }}^{C O}$ values are calculated for those binary alloys that showed the most negative $\Delta E_{\text {seg }}$ on both (100) and (211) surfaces under vacuum conditions (e.g. Ir/Ag, Rh/Ag). These "reactive" dopants (i.e. Rh and Ir) have significantly higher surface energies, as well as smaller lattice constants than Ag. ${ }^{67}$ This difference in the lattice constants introduces strain effects, thereby reducing further any electronic overlap between dopant and coinage atoms. ${ }^{65}$ In turn, the accumulated electron density on the Ir and $\mathrm{Rh}$ atom sites could be mitigated either by an increase in the coordination number (i.e. immerse into the bulk of the coinage metal), or by coupling with a CO molecule. Similarly, one may explain why those SAAs exhibiting less negative $\Delta E_{\text {seg }}$ under vacuum conditions yield relatively small positive values of $\Delta E_{\text {seg }}^{C O}$. For example the surface energies of $\mathrm{Pd}$ and $\mathrm{Ag}$ are not significantly different ${ }^{67}$ and the same holds for their 
RPBE lattice constants (4.00 and 4.23 for $\mathrm{Pd}$ and $\mathrm{Ag}$, respectively). In turn, for $\mathrm{Pd} / \mathrm{Ag}$ we find a slightly negative $\Delta E_{\text {seg }}$ and a relatively small positive value of $\Delta E_{\text {seg }}^{C O}$.

\subsection{Surface aggregation studies}

We continue by presenting our study on the surface aggregation of dopant atoms on highly dilute alloys, in the presence versus in the absence of $\mathrm{CO}$. We calculate the aggregation energy $\left(\Delta E_{\text {agg }}\right)$ for thirteen bimetallic alloys using Eq. (4). $\Delta E_{\text {agg }}$ quantifies the preference of dopant atoms to form aggregates and clusters, such as dimers, trimers and islands from a dispersed SAA phase. In this case, we explicitly considered "small" dopant clusters, such as dimers and trimers, assuming that dopant atom loadings at the limit of high dilution will be less than $1 \%$ and therefore, entropic forces will make the formation of larger aggregates unlikely for miscible metal combinations. ${ }^{12,22,69}$

We examined different dopant dimer configurations on (100) and (211) surfaces (Figure 8). On the (211) step, we investigated a dimer that is formed by neighbouring dopant atoms on the edge. On the (100) surface we considered two dimers, with the dopant atoms being either first nearest neighbours (1NN) or second nearest neighbours (2NN) (Figure 8). We performed calculations on the dimer slabs of the thirteen stable bimetallic alloys and using Eq. (4) we computed $\Delta E_{a g g}$ (Figure 8(a)). We determine that most Cu-based alloys have a strong thermodynamic preference for dispersion to the SAA phase $\left(\Delta E_{a g g}>0\right)$ on both (211) and (100) surfaces (Figure 8(a)); this is in good agreement with other theoretical and experimental works and indeed our previous work on the (111) facet. ${ }^{9,69-71}$

We find that the SAA phase is also thermodynamically favoured for most of Au- and Ag-based alloys under vacuum conditions. Yet, we compute $\Delta E_{a g g}<0$ on $\operatorname{Ir} / \mathrm{Cu}(100), \operatorname{Ir} / \mathrm{Cu}(211), \operatorname{Ir} / \operatorname{Ag}(211)$ and $\operatorname{Ir} / \operatorname{Ag}(100)$, where there is clear thermodynamic propensity for forming edge and (100) 1NN dimers. The presence of strong Ir-Ir interactions in dimer configurations is also evidenced by the smaller relaxed distance between adjacent Ir atoms in dimers, as compared to adjacent atoms in pure Ir metal surfaces. For example, we find an Ir-Ir distance of $2.46 \AA$ on the (211) dimer of $\operatorname{Ir} / \mathrm{Ag}$, whilst the corresponding $\operatorname{Ir}-\mathrm{Ir}$ distance on pure $\operatorname{Ir}(211)$ is $2.75 \AA$. However, when the two Ir atoms are arranged in a $2 \mathrm{NN}$ dimer on (100) the distance between them is greater than that in the $1 \mathrm{NN}$ (100) dimer, and we compute $\Delta E_{a g g}>0$ for the $2 \mathrm{NN}$ dimer (Figure 8 (a)). For example, on $\mathrm{Ir} / \mathrm{Cu}(100)$ the relaxed distances between dopants of $1 \mathrm{NN}$ and $2 \mathrm{NN}$ dimers are $2.53 \AA$ and 3.18 $\AA$, respectively, and we find $\Delta E_{a g g}=-0.08 \mathrm{eV}$ and $+0.09 \mathrm{eV}$, respectively. Finally, in some cases we find $\Delta E_{\text {agg }} \approx 0.0 \mathrm{eV}$ (e.g. $\left.\mathrm{Rh} / \mathrm{Ag}(211), \mathrm{Rh} / \mathrm{Au}(211)\right)$. One would expect that when accounting for entropic effects in these cases, and those with slightly negative $\Delta E_{a g g}$, will result in dopant atom dispersion.

Finally, we investigate the aggregation behaviour of the same binary alloys in the presence of $\mathrm{CO}$, exploring the idea of controlling the size of dopant ensemble by tuning P CO. $^{21,32}$ First, we simulate "low PCO" conditions, whereby full saturation of all dopant atoms in the dimer configurations is not possible. To capture representative configurations for such conditions, we performed DFT calculations with only one CO adsorbed on the most stable adsorption site on the edge, (100) $1 \mathrm{NN}$ and (100) $2 \mathrm{NN}$ aggregates. In all alloys the most 
stable site for $\mathrm{CO}$ adsorption on the (100) $2 \mathrm{NN}$ dimer is a dopant top site. By contrast, the most stable adsorption site on edge and (100) 1NN dimers is the two-fold bridge site between two adjacent dopant atoms, with the exception of $\mathrm{Ir} / \mathrm{Cu}$ and $\mathrm{Ir} / \mathrm{Ag}$ alloys, where the top dopant site is the most stable. Configurations in the relaxed state of these latter cases are shown in Figure 9.

Using the corresponding adsorption energy values $\left(E_{a d s}^{n-m e r}(C O)\right)$, where $n$-mer corresponds to a dimer in this case, we calculate $\Delta E_{a g g}^{1 \times C O}$ (Figure 8(b)). The main observation is that all Ag-and Au-based alloys show a thermodynamic preference to forming (1NN) aggregates on the (100) facet and (211) edges in the presence of $\mathrm{CO}$. This is also true for $\mathrm{Ni} / \mathrm{Cu}$, where dispersion of $\mathrm{Ni}$ atoms was preferred under vacuum conditions (Figure 8(a)). It should be noted that the same shift regarding the preference for aggregate formation has been observed upon $\mathrm{C}_{2} \mathrm{H}_{2}$ adsorption on $\mathrm{Ni} / \mathrm{Cu}(111) .{ }^{72}$ We find that the type of the most stable adsorption site is crucial to the stability of the aggregate phase versus the SAA phase. In particular, the formation of (100) $1 \mathrm{NN}$ and edge dimers is promoted on the binary alloys where $\mathrm{CO}$ prefers the two-fold site in-between adjacent dopant atoms (e.g. Pt/Ag, Pt/Au, Pd/Ag etc.). When bound to two neighbouring dopants, $\mathrm{CO}$ interacts with both dopants, thereby keeping them together by forming a stable dimer. Quite the contrary is observed when $\mathrm{CO}$ is more stable on the top dopant site, which is true for $\mathrm{Ir} / \mathrm{Ag}$ and $\mathrm{Ir} / \mathrm{Cu}$ (100) $1 \mathrm{NN}$ and edge dimers, as well as on (100) 2NN dimers of all the binary alloys. Under these circumstances, CO interacts strongly with the atom where it is adsorbed and tends to isolate it from the neighbouring dopant. For example, under vacuum conditions the formation of (100) $1 \mathrm{NN}$ and edge dimers was favoured on $\operatorname{Ir} / \mathrm{Cu}(211)$ and $\operatorname{Ir} / \mathrm{Cu}(100)\left(\Delta E_{a g g}^{1 \times C O}\right.$ $=-0.13 \mathrm{eV}$ and $-0.08 \mathrm{eV}$, respectively, as shown in Figure 8(a)). In contrast to all other cases, addition of a $\mathrm{CO}$ on these configurations, brought about slight preference for the SAA phase $\left(\Delta E_{a g g}^{1 \times C O}=+0.01 \mathrm{eV}\right.$ and + $0.03 \mathrm{eV}$, respectively, as shown in Figure 8(b)) instead of further promoting the formation of aggregates. 

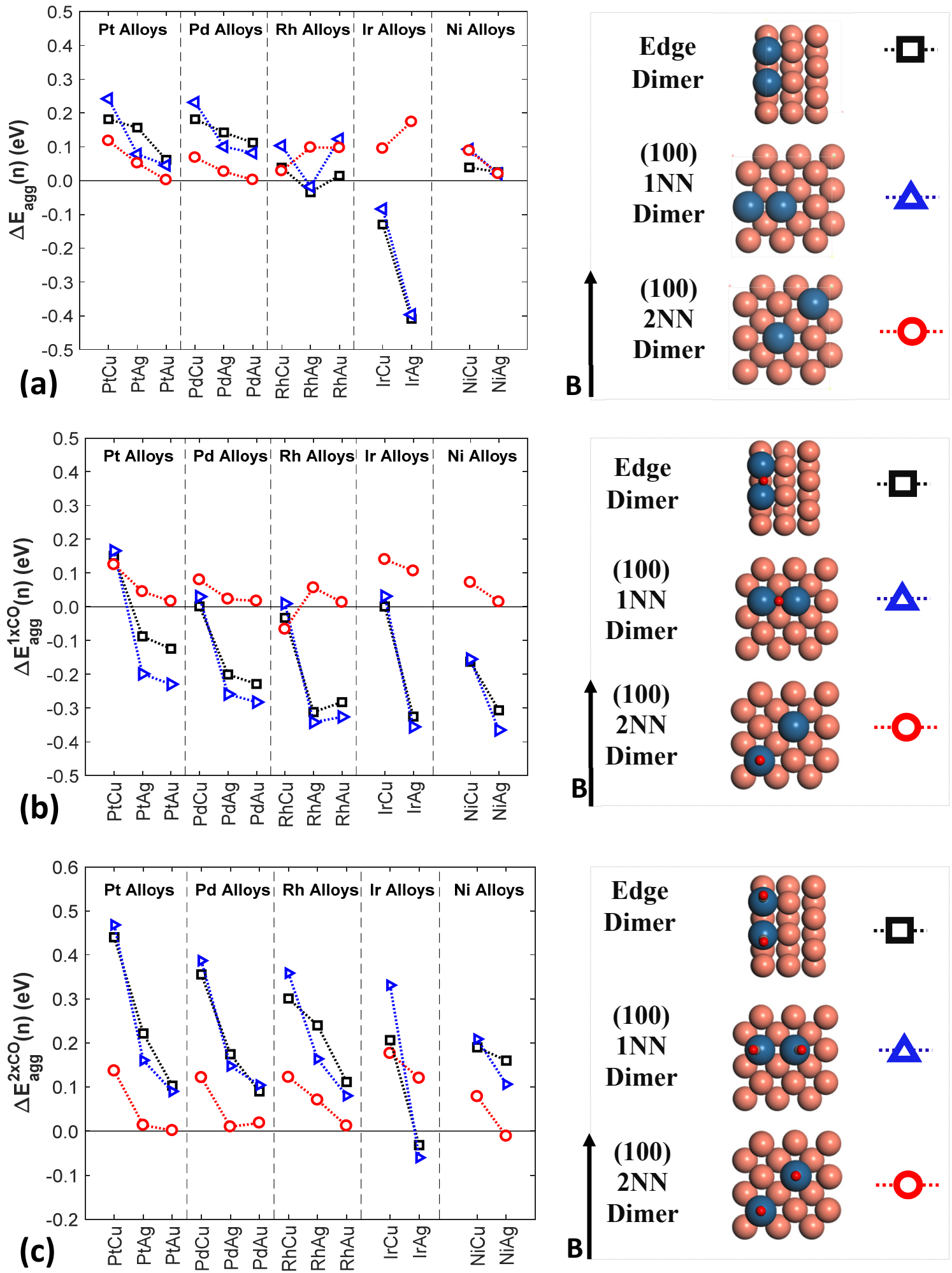

Figure 8. Aggregation energies $\left(\Delta E_{a g g}\right)$ for dimers relative to the SAA phase of $\mathrm{Ni}, \mathrm{Pd}, \mathrm{Pt}, \mathrm{Rh}$ and $\mathrm{Ir}$ doped into the (100) and (211) surfaces of the group 11 metals with (a) no adsorbed CO molecule; (b) 1 adsorbed CO molecule; and (c) 2 adsorbed $\mathrm{CO}$ molecules. The legends next to each plot show dimer configurations in the relaxed state. Therein carbon, coinage metal, dopant metal and oxygen atoms are represented by grey, orange, blue and red spheres, respectively.

To simulate higher $\mathrm{CO}$ coverages we add a $2^{\text {nd }} \mathrm{CO}$ molecule in our DFT calculations, with both adsorbates placed on the two dopant top sites. The underlying assumption is that the $\mathrm{P}_{\mathrm{CO}}$ in a surface science experiment will be high enough so that the dopant atoms are covered with CO (partially or fully), but also low enough so that the host coinage metal is free of $\mathrm{CO}$. This would be possible due to the significant difference between 
adsorption energies on each metal atom within the alloy. In this case, the CO-CO lateral interactions become prominent and force the dispersion of the dopant atoms on the (211) and (100) coinage metal surfaces. We see that the SAA phase is strongly preferred over the dimer phase under full CO dopant coverage conditions (Figure 8(c)) in agreement with calculations on the (111) facet. ${ }^{33}$ The formation of (100) $1 \mathrm{NN}$ and edge dimers is rarely thermodynamically favoured, with the only exception being $\mathrm{Ir} / \mathrm{Ag}$. For this particular system, there is a slight preference for aggregation with $\Delta E_{a g g}^{2 \times C O}=-0.06 \mathrm{eV}$ and $-0.03 \mathrm{eV}$ for (100) $1 \mathrm{NN}$ and edge dimers, respectively. These $\Delta E_{a g g}^{2 \times C O}$ values are, however, close to zero. They are significantly less negative than the corresponding $\Delta E_{\text {agg }}$ obtained under vacuum (i.e. $-0.40 \mathrm{eV}$ and $-0.41 \mathrm{eV}$, respectively), and so when subjected to entropic forces may result in dispersion.

Interestingly, the number of $\mathrm{CO}$ molecules bound to dopant cluster has little effect on the thermodynamic preference for forming (100) $2 \mathrm{NN}$ aggregates. In the presence of a single $\mathrm{CO}$ adsorbed on these configurations, the stable adsorption site is the dopant top site for all binary alloys, so aggregation cannot be promoted using CO. This could be enabled, however, using larger adsorbates that are also bidentate (e.g. $\left.\mathrm{C}_{2} \mathrm{H}_{2}\right)$ or chelating. ${ }^{72}$ In addition to the weak interactions between dopant atoms of the (100) $2 \mathrm{NN}$ dimer, we find that CO-CO interactions are also small as a result of the large distance between the dopant atoms. This is reflected by the relaxed geometry of the two $\mathrm{CO}$ molecules, which remain sharply vertical to the dopant top sites (see bottom inset in the legend of Figure 8(c)).
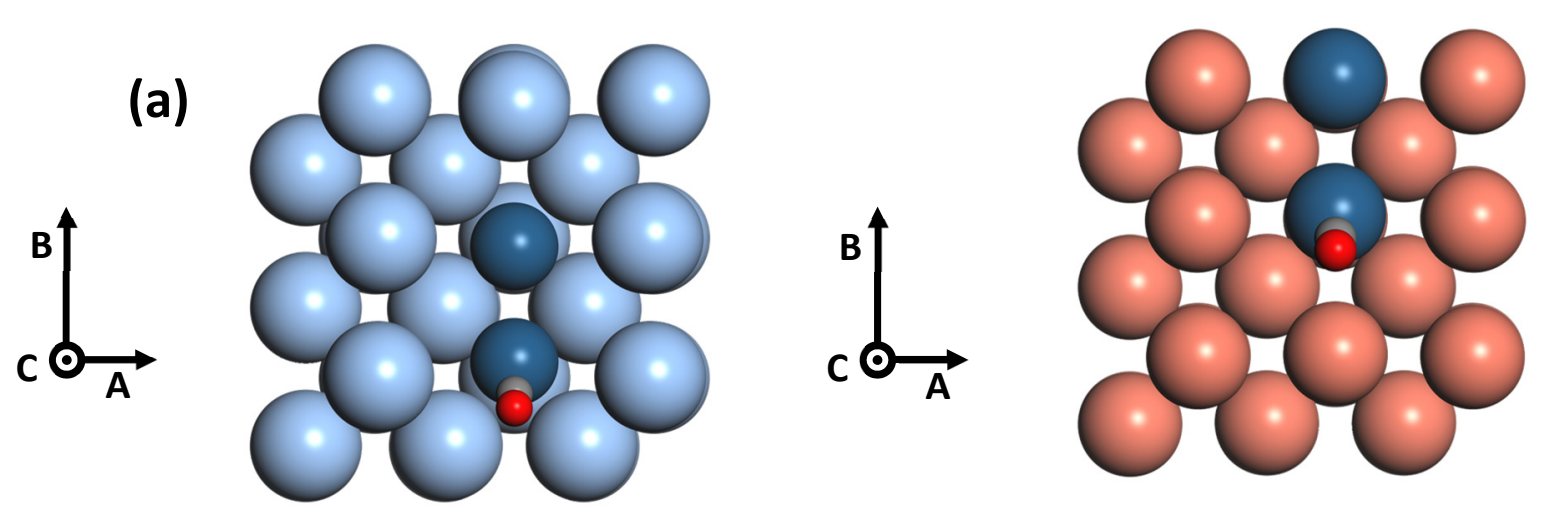

(b)
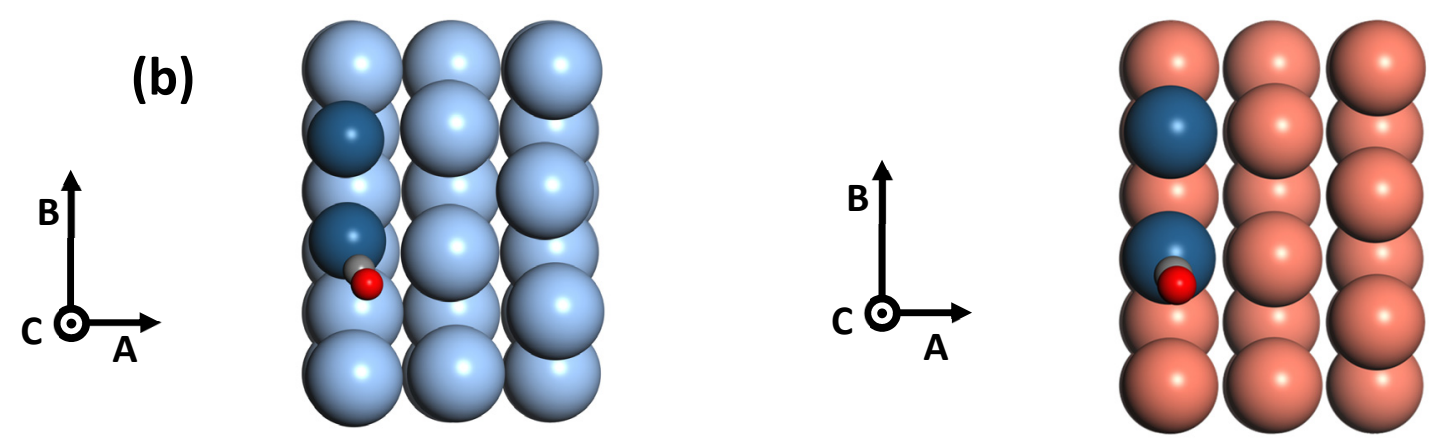

Figure 9. Panel (a) shows (100) $1 \mathrm{NN}$ dimers, whereon a CO molecule is adsorbed on the most stable site, of Ir/Ag (figure on the left) and $\mathrm{Ir} / \mathrm{Cu}$ (figure on the right) alloys in a relaxed state. Panel (b) shows a (211) dimers, whereon a $\mathrm{CO}$ molecule is adsorbed on the most stable site, of $\mathrm{Ir} / \mathrm{Ag}$ (figure on the left) and $\mathrm{Ir} / \mathrm{Cu}$ (figure on the right) alloys in a relaxed state. Carbon, oxygen, iridium and copper atoms are represented by grey, red, blue and orange spheres, respectively. 
Finally, aggregation for trimer configurations, in the presence versus in the absence of CO, is analysed in a similar manner and the results are presented in the supplementary material. Aggregation energies, $\Delta E_{a g g}$, are calculated under vacuum conditions, and in the presence of $1 \times \mathrm{CO}, 2 \times \mathrm{CO}$ and $3 \times \mathrm{CO}$. We find that at full $\mathrm{CO}$ dopant fractional coverage the SAA phase is favoured, whilst in the presence of $1 \times \mathrm{CO}$ the formation of (100) and (211) trimers will be thermodynamically facilitated for all $\mathrm{Ag}$ - and $\mathrm{Au}$-based alloys as well as for $\mathrm{Ni} / \mathrm{Cu}$. For more details, the reader is referred to the supplementary material of this work.

\section{Concluding Remarks}

In summary, we have performed DFT calculations to study the adsorption behaviour of CO on highly dilute binary metal alloys, relating the strength of binding to poisoning resistance, comparing surface interactions across several facets and investigating the stability of low dopant loading structures in the presence and absence of CO. Our results suggest that both (100) and (211) SAA surfaces exhibit high resistance to $\mathrm{CO}$ poisoning when employing Pt and Pd dopants. By contrast, Ir and Rh SAAs tend to bind CO very strongly and are therefore expected to be more susceptible to $\mathrm{CO}$ poisoning as compared to their monometallic dopant counterparts.

We have shown that the calculated $\mathrm{Eads}_{\mathrm{S}}(\mathrm{CO})$ on SAA (111), (100) and (211) facets correlate well with each other and the binding strength shows the following trend: $(211)>(100) \approx(111)$. Interestingly, with regard to CO adsorption, the (111) and (100) SAA surfaces behave similarly, even though their topmost layer atoms have different coordination and generalised coordination numbers (the latter is 7.5 and 6.6 for (111) and (100) respectively). ${ }^{73} \mathrm{On}$ this basis, we point out that if $\mathrm{E}_{\mathrm{ads}}(\mathrm{CO})$ represents an activity descriptor, one should expect similar reactivity in structure sensitive reactions occurring on (111) and (100) SAA surfaces. It then follows that during the bottom-up design of new SAA materials, one may draw conclusions regarding the reactivity of one facet based on the other, which will be of great importance in truncating the search for optimal heterogeneous catalysts. Moreover, the stronger binding on (211) SAA surfaces is attributed to electronic and geometric effects, which make edge sites distinct as compared to planar surface sites, even at the SAA limit. In contrast, for dopant dimers we have demonstrated that the binding strength trend is: $(211)>(100)>(111)$. This is the expected trend for pure metals according to the $d$-band model of Hammer and Nørskov ${ }^{64}$ and agrees well with the hypothesis that lower coordination numbers result in higher energies of $d$ states. ${ }^{63}$

Regarding the segregation of the dopant atom, we showed that under vacuum conditions there is a clear thermodynamic preference of the dopant atom to be immersed in the bulk matrix of the coinage metal for the majority of binary combinations. This could deteriorate catalytic performance, as the dopant would not be able to participate in catalysis and promote reactions. By contrast, in the presence of CO the most stable structures are those with the dopant atom on the topmost layers. This is because of the strong dopant-CO interaction and is true for both (100) and (211) surfaces. Notably, the dopant metal atoms with the strongest preference of segregating into the bulk of the coinage metal, form the most stable surface alloys in the presence of $\mathrm{CO}$ (e.g. Ir/Ag, $\mathrm{Rh} / \mathrm{Ag}$ and $\mathrm{Ir} / \mathrm{Au}$ in both (211) and (100) surfaces). This is the result of Ir or Rh atoms 
needing to share electron density by either coupling with an adsorbate or by relocation to the bulk of the coinage metal, thereby increasing their coordination number.

Finally, our calculations suggest that control over the formation of dopant aggregates on Ag-and Au-based alloys could be achieved by tuning the $\mathrm{CO}$ fractional coverage of dopant aggregates. The same can be accomplished on $\mathrm{Ni} / \mathrm{Cu}$ and $\mathrm{Ir} / \mathrm{Cu}$, whereas $\mathrm{Pt} / \mathrm{Cu}, \mathrm{Pd} / \mathrm{Cu}$ and $\mathrm{Rh} / \mathrm{Cu}$ alloys show a thermodynamic preference for the SAA phase even in the presence of CO. However, in these materials it is conceivable that larger, multidentate absorbates may be able to induce aggregation. ${ }^{72}$ Future studies can investigate this possibility, but also identify the chemical potentials of adsorbates that would stabilise aggregate ensembles with desired catalytic performance for reactions of interest.

\section{Supplementary Material}

See Supplementary Material for surface aggregation studies on trimers, k-point convergence tests on (100) and (211) and details on the (211) segregation calculations.

\section{Acknowledgement}

M. T. D. is supported by the EPSRC Doctoral Prize Fellowship, grant reference number EP/N509577/1. The authors gratefully acknowledge the use of the UCL High Performance Computing Facility Legion@UCL and Grace@UCL in the completion of the simulations of this work. K. G. P. would like to thank Dr Romain Réocreux for fruitful discussions.

\section{References}

(1) Kakaei, K.; Esrafili, M. D.; Ehsani, A. Introduction to Catalysis. In Graphene Surfaces Particles and Catalysts; 2019; pp 1-21.

(2) Simonovis, J. P.; Hunt, A.; Palomino, R. M.; Senanayake, S. D.; Waluyo, I. Enhanced Stability of Pt$\mathrm{Cu}$ Single-Atom Alloy Catalysts: In Situ Characterization of the $\mathrm{Pt} / \mathrm{Cu}(111)$ Surface in an Ambient Pressure of CO. J. Phys. Chem. C 2018, 122 (8), 4488-4495.

(3) Kustov, A. L.; Frey, A. M.; Larsen, K. E.; Johannessen, T.; Nørskov, J. K.; Christensen, C. H. CO Methanation over Supported Bimetallic Ni-Fe Catalysts: From Computational Studies towards Catalyst Optimization. Appl. Catal. A Gen. 2007, 320, 98-104.

(4) Takehiro, N.; Liu, P.; Bergbreiter, A.; Nørskov, J. K.; Behm, R. J. Hydrogen Adsorption on Bimetallic PdAu(111) Surface Alloys: Minimum Adsorption Ensemble, Ligand and Ensemble Effects, and Ensemble Confinement. Phys. Chem. Chem. Phys. 2014, 16 (43), 23930-23943.

(5) Besenbacher, F.; Chorkendorff, I.; Clausen, B. S.; Hammer, B.; Molenbroek, A. M.; Nørskov, J. K.; Stensgaard, I. Design of a Surface Alloy Catalyst for Steam Reforming. Science (80-. ). 1998, 279 (5358), 1913-1915.

(6) Dhifallah, M.; Dhouib, A.; Aldulaijan, S.; Renzo, F.; Guesmi, H. First-Principles Study of Au-Cu Alloy Surface Changes Induced by Gas Adsorption of CO, NO, or O2. J. Chem. Phys. 2016, 145 (2).

(7) Chorkendorff, I.; Niemantsverdriet, J. W. Introduction to Catalysis. In Concepts of Modern Catalysis and Kinetics; Wiley-VCH Verlag GmbH \& Co. KGaA: Weinheim, FRG, 2003; pp 1-21. 
(8) Alexeev, O. S.; Gates, B. C. Supported Bimetallic Cluster Catalysts. Ind. Eng. Chem. Res. 2003, 42 (8), 1571-1587.

(9) Kyriakou, G.; Boucher, M. B.; Jewell, A. D.; Lewis, E. a; Lawton, T. J.; Baber, A. E.; Tierney, H. L.; Flytzani-stephanopoulos, M.; Sykes, E. C. H. Isolated Metal Atom Geometries as a Strategy for Selective Heterogeneous Hydrogenations. Science 2012, 335 (March), 1209-1212.

(10) Darby, M. T.; Stamatakis, M.; Michaelides, A.; Sykes, E. C. H. Lonely Atoms with Special Gifts: Breaking Linear Scaling Relationships in Heterogeneous Catalysis with Single-Atom Alloys. J. Phys. Chem. Lett. 2018, 9 (18), 5636-5646.

(11) Boucher, M. B.; Zugic, B.; Cladaras, G.; Kammert, J.; Marcinkowski, M. D.; Lawton, T. J.; Sykes, E. C. H.; Flytzani-Stephanopoulos, M. Single Atom Alloy Surface Analogs in Pd0.18Cu15nanoparticles for Selective Hydrogenation Reactions. Phys. Chem. Chem. Phys. 2013, 15 (29), 12187-12196.

(12) Tierney, H. L.; Baber, A. E.; Kitchin, J. R.; Sykes, E. C. H. Hydrogen Dissociation and Spillover on Individual Isolated Palladium Atoms. Phys. Rev. Lett. 2009, 103 (24), 1-4.

(13) Chen, M.; Kumar, D.; Yi, C.-W.; Goodman, D. W. The Promotional Effect of Gold in Catalysis by Palladium-Gold. Science (80-. ). 2005, 310 (5746), 291-293.

(14) Liu, J.; Lucci, F. R.; Yang, M.; Lee, S.; Marcinkowski, M. D.; Therrien, A. J.; Williams, C. T.; Sykes, E. C. H.; Flytzani-Stephanopoulos, M. Tackling CO Poisoning with Single-Atom Alloy Catalysts. $J$. Am. Chem. Soc. 2016, 138 (20), 6396-6399.

(15) Pei, G. X.; Liu, X. Y.; Wang, A.; Lee, A. F.; Isaacs, M. A.; Li, L.; Pan, X.; Yang, X.; Wang, X.; Tai, Z.; et al. Ag Alloyed Pd Single-Atom Catalysts for Efficient Selective Hydrogenation of Acetylene to Ethylene in Excess Ethylene. ACS Catal. 2015, 5 (6), 3717-3725.

(16) Shan, J.; Lucci, F. R.; Liu, J.; El-Soda, M.; Marcinkowski, M. D.; Allard, L. F.; Sykes, E. C. H.; Flytzani-Stephanopoulos, M. Water Co-Catalyzed Selective Dehydrogenation of Methanol to Formaldehyde and Hydrogen. Surf. Sci. 2016, 650, 121-129.

(17) Marcinkowski, M. D.; Darby, M. T.; Liu, J.; Wimble, J. M.; Lucci, F. R.; Lee, S.; Michaelides, A.; Flytzani-Stephanopoulos, M.; Stamatakis, M.; Sykes, E. C. H. Pt/Cu Single-Atom Alloys as CokeResistant Catalysts for Efficient C-H Activation. Nat. Chem. 2018, 10 (3), 325-332.

(18) Miura, H.; Endo, K.; Ogawa, R.; Shishido, T. Supported Palladium-Gold Alloy Catalysts for Efficient and Selective Hydrosilylation under Mild Conditions with Isolated Single Palladium Atoms in Alloy Nanoparticles as the Main Active Site. ACS Catal. 2017, 7 (3), 1543-1553.

(19) Yang, C.; Miao, Z.; Zhang, F.; Li, L.; Liu, Y.; Wang, A.; Zhang, T. Hydrogenolysis of Methyl Glycolate to Ethanol over a Pt-Cu/SiO2single-Atom Alloy Catalyst: A Further Step from Cellulose to Ethanol. Green Chem. 2018, 20 (9), 2142-2150.

(20) Gao, F.; Wang, Y.; Goodman, D. W. Reaction Kinetics and Polarization-Modulation Infrared Reflection Absorption Spectroscopy ( PM-IRAS ) Investigation of CO Oxidation over Supported Pd Au Alloy Catalysts. J. Phys. Chem. C 2010, 114 (2), 4036-4043.

(21) Gao, F.; Wang, Y.; Goodman, D. W. CO Oxidation over AuPd(100) from Ultrahigh Vacuum to nearAtmospheric Pressures: CO Adsorption-Induced Surface Segregation and Reaction Kinetics. J. Phys. Chem. C 2009, 113 (33), 14993-15000.

(22) Lucci, F. R.; Darby, M. T.; Mattera, M. F. G.; Ivimey, C. J.; Therrien, A. J.; Michaelides, A.; Stamatakis, M.; Sykes, E. C. H. Controlling Hydrogen Activation, Spillover, and Desorption with PdAu Single-Atom Alloys. J. Phys. Chem. Lett. 2016, 7 (3), 480-485.

(23) Gao, F.; Wang, Y.; Goodman, D. W. CO Oxidation over AuPd(100) from Ultrahigh Vacuum to nearAtmospheric Pressures: The Critical Role of Contiguous Pd Atoms. J. Am. Chem. Soc. 2009, 131 (16), 5734-5735. 
(24) Li, Q.; Song, L.; Pan, L.; Zhuang, X.; Ling, M.; Duan, L. Ensemble and Ligand Effects on the Acetylene Adsorption on Ordered PdxAg1-x/Pd(100) Surface Alloys Investigated by Periodic DFT Study. Phys. Chem. Chem. Phys. 2013, 15 (46), 20345-20353.

(25) Liu, P.; Nørskov, J. K. Ligand and Ensemble Effects in Adsorption on Alloy Surfaces. Phys. Chem. Chem. Phys. 2001, 3, 3814-3818.

(26) Takehiro, N.; Liu, P.; Bergbreiter, A.; Nørskov, J. K.; Behm, R. J. Hydrogen Adsorption on Bimetallic PdAu(111) Surface Alloys: Minimum Adsorption Ensemble, Ligand and Ensemble Effects, and Ensemble Confinement. Phys. Chem. Chem. Phys. 2014, 16 (43), 23930-23943.

(27) Zafeiratos, S.; Piccinin, S.; Teschner, D. Alloys in Catalysis: Phase Separation and Surface Segregation Phenomena in Response to the Reactive Environment. Catal. Sci. Technol. 2012, 2 (9), 1787-1801.

(28) Sansa, M.; Dhouib, A.; Guesmi, H. Density Functional Theory Study of CO-Induced Segregation in Gold-Based Alloys. J. Chem. Phys. 2014, 141 (6), 64709.

(29) Khanra, B. C.; Bertolini, J. C.; Rousset, J. L. Effect of Surface Segregation on the Catalytic Activity of Alloys: CO Hydrogenation on Pd-Ni(111) Surface. J. Mol. Catal. A Chem. 1998, 129 (2-3), 233240.

(30) Soto-Verdugo, V.; Metiu, H. Segregation at the Surface of an Au/Pd Alloy Exposed to CO. Surf. Sci. 2007, 601 (23), 5332-5339.

(31) Løvvik, O. M.; Opalka, S. M. Reversed Surface Segregation in Palladium-Silver Alloys due to Hydrogen Adsorption. Surf. Sci. 2008, 602 (17), 2840-2844.

(32) McCue, A. J.; Anderson, J. A. CO Induced Surface Segregation as a Means of Improving Surface Composition and Enhancing Performance of CuPd Bimetallic Catalysts. J. Catal. 2015, 329, 538546.

(33) Darby, M. T.; Sykes, E. C. H.; Michaelides, A.; Stamatakis, M. Carbon Monoxide Poisoning Resistance and Structural Stability of Single Atom Alloys. Top. Catal. 2018, 61 (5-6), 428-438.

(34) Dhouib, A.; Guesmi, H. DFT Study of the M Segregation on MAu Alloys (M = Ni, Pd, Pt) in Presence of Adsorbed Oxygen O and O2. Chem. Phys. Lett. 2012, 521, 98-103.

(35) Cairon, O.; Guesmi, H. How Does CO Capture Process on Microporous NaY Zeolites? A FTIR and DFT Combined Study. Phys. Chem. Chem. Phys. 2011, 13 (23), 11430-11437.

(36) Bliem, R.; van der Hoeven, J. E. S.; Hulva, J.; Pavelec, J.; Gamba, O.; de Jongh, P. E.; Schmid, M.; Blaha, P.; Diebold, U.; Parkinson, G. S. Dual Role of CO in the Stability of Subnano Pt Clusters at the $\mathrm{Fe}_{3} \mathrm{O}_{4}$ (001) Surface. Proc. Natl. Acad. Sci. 2016, 113 (32), 8921-8926.

(37) Parkinson, G. S.; Novotny, Z.; Argentero, G.; Schmid, M.; Pavelec, J.; Kosak, R.; Blaha, P.; Diebold, U. Carbon Monoxide-Induced Adatom Sintering in a Pd-Fe3O4model Catalyst. Nat. Mater. 2013, 12 (8), 724-728.

(38) Zhu, B.; Thrimurthulu, G.; Delannoy, L.; Louis, C.; Mottet, C.; Creuze, J.; Legrand, B.; Guesmi, H. Evidence of Pd Segregation and Stabilization at Edges of AuPd Nano-Clusters in the Presence of CO: A Combined DFT and DRIFTS Study. J. Catal. 2013, 308, 272-281.

(39) Yao, Y.; Goodman, D. W. In Situ IR Spectroscopic Studies of Ni Surface Segregation Induced by CO Adsorption on $\mathrm{Cu}-\mathrm{Ni} / \mathrm{SiO} 2$ bimetallic Catalysts. Phys. Chem. Chem. Phys. 2014, 16 (8), 3823-3829.

(40) Kresse, G.; Furthmüller, J. Efficiency of Ab-Initio Total Energy Calculations for Metals and Semiconductors Using a Plane-Wave Basis Set. Comput. Mater. Sci. 1996, 6 (1), 15-50.

(41) G. Kresse; J.Hafner. Ab Initio Molecular Dynamics for Liquid Metals. Phys. Rev. B 1993, 47 (1), $558-561$. 
(42) Blöchl, P. E. Projector Augmented-Wave Method. Phys. Rev. B 1994, 50 (24), 17953-17979.

(43) Perdew, J. P.; Burke, K.; Ernzerhof, M. Generalized Gradient Approximation Made Simple. Phydical Rev. Lett. 1996, 77 (18), 3865-3868.

(44) Hammer, B.; Hansen, L. B.; Nørskov, J. K. Improved Adsorption Energetics within DensityFunctional Theory Using Revised Perdew-Burke-Ernzerhof Functionals. Phys. Rev. B 1999, 59 (11), 7413-7421.

(45) Nørskov, J. K.; Studt, F.; Abild-Pedersen, F.; Bligaard, T. The Potential Energy Diagram. In Fundamental Concepts in Heterogeneous Catalysis; John Wiley \& Sons, Inc: Hoboken, NJ, USA, 2014; pp 1-20.

(46) Papanikolaou, K. G.; Darby, M. T.; Stamatakis, M. Adlayer Structure and Lattice Size Effects on Catalytic Rates Predicted from KMC Simulations: NO Oxidation on Pt(111). J. Chem. Phys. 2018, 149 (18), 184701.

(47) Ni, B.; Wang, X. Face the Edges: Catalytic Active Sites of Nanomaterials. Adv. Sci. 2015, 2 (7), 1500085 .

(48) Abild-Pedersen, F.; Greeley, J.; Nørskov, J. K. Understanding the Effect of Steps, Strain, Poisons, and Alloying: Methane Activation on Ni Surfaces. Catal. Letters 2005, 105 (1-2), 9-13.

(49) Andersson, M. P.; Abild-Pedersen, F.; Remediakis, I. N.; Bligaard, T.; Jones, G.; Engbæk, J.; Lytken, O.; Horch, S.; Nielsen, J. H.; Sehested, J.; et al. Structure Sensitivity of the Methanation Reaction: H2-Induced CO Dissociation on Nickel Surfaces. J. Catal. 2008, 255 (1), 6-19.

(50) Mulla, S. S.; Chen, N.; Cumaranatunge, L.; Blau, G. E.; Zemlyanov, D. Y.; Delgass, W. N.; Epling, W. S.; Ribeiro, F. H. Reaction of NO and O2to NO2on Pt: Kinetics and Catalyst Deactivation. $J$. Catal. 2006, 241 (2), 389-399.

(51) Dimakis, N.; Navarro, N. E.; Mion, T.; Smotkin, E. S. Carbon Monoxide Adsorption Coverage Study on Platinum and Ruthenium Surfaces. J. Phys. Chem. C 2014, 118, 11711-11722.

(52) Dimakis, N.; Flor, F. A.; Navarro, N. E.; Salgado, A.; Smotkin, E. S. Adsorption of Carbon Monoxide on Platinum - Ruthenium, Platinum - Osmium, Platinum - Ruthenium - Osmium, and Platinum Ruthenium - Osmium - Iridium Alloys. J. Phys. Chem. C 2016, 120, 10427-10441.

(53) Soini, T. M.; Krüger, S.; Rösch, N. The DFT + Umol Method and Its Application to the Adsorption of CO on Platinum Model Clusters. J. Chem. Phys. 2014, 140, 174709.

(54) Kresse, G.; Gil, A.; Sautet, P. Significance of Single-Electron Energies for the Description of CO on $\operatorname{Pt}(111)$. 2003, 3-6.

(55) Vollmer, S.; Witte, G.; Wöll, C. No Title. Catal. Letters 2001, 77 (1/3), 97-101.

(56) Nakamura, I.; Suzuki, K.; Takahashi, a.; Haneda, M.; Hamada, H.; Fujitani, T. Reaction Properties of NO and CO over an Ir(211) Surface. J. Vac. Sci. Technol. A Vacuum, Surfaces, Film. 2007, 25 (4), 1143.

(57) Creighan, S. C.; Mukerji, R. J.; Bolina, A. S.; Lewis, D. W.; Brown, W. A. The Adsorption of CO on the Stepped Pt $\{211\}$ Surface: A Comparison of Theory and Experiment. Catal. Letters 2003, 88 (12), 39-45.

(58) Thirumalai, H.; Kitchin, J. R. Investigating the Reactivity of Single Atom Alloys Using Density Functional Theory. Top. Catal. 2018, 61 (5-6), 462-474.

(59) Darby, M. T.; Réocreux, R.; Sykes, E. C. H.; Michaelides, A.; Stamatakis, M. Elucidating the Stability and Reactivity of Surface Intermediates on Single-Atom Alloy Catalysts. ACS Catal. 2018, 8 (6), 5038-5050.

(60) Gameel, K. M.; Sharafeldin, I. M.; Abourayya, A. U.; Biby, A. H.; Allam, N. K. Unveiling CO 
Adsorption on Cu Surfaces: New Insights from Molecular Orbital Principles. Phys. Chem. Chem. Phys. 2018, 20, 25892-25900.

(61) Trac Y, J. C. Structural Influences on Adsorption Energy. II. CO on Ni(100). J. Chem. Phys. 1972, 56 (6), 2748-2754.

(62) Basagiannis, A. C.; Verykios, X. E. Catalytic Steam Reforming of Acetic Acid for Hydrogen Production. Int. J. Hydrogen Energy 2007, 32 (15 SPEC. ISS.), 3343-3355.

(63) Jiang, T.; Mowbray, D. J.; Dobrin, S.; Falsig, H.; Hvolbæk, B.; Bligaard, T.; Nørskov, J. K. Trends in CO Oxidation Rates for Metal Nanoparticles and Close-Packed, Stepped, and Kinked Surfaces. $J$. Phys. Chem. C 2009, 113 (24), 10548-10553.

(64) Hammer, B.; Nørskov, J. K. Electronic Factors Determining the Reactivity of Metal Surfaces. Surf. Sci. 1995, 343 (3), 211-220.

(65) Nørskov, J. K.; Studt, F.; Abild-Pedersen, F.; Bligaard, T. The Electronic Factor in Heterogeneous Catalysis. In Fundamental Concepts in Heterogeneous Catalysis; John Wiley \& Sons, Inc: Hoboken, NJ, USA, 2014; pp 114-137.

(66) Calle-Vallejo, F.; Loffreda, D.; Koper, M. T. M.; Sautet, P. Introducing Structural Sensitivity into Adsorption-Energy Scaling Relations by Means of Coordination Numbers. Nat. Chem. 2015, 7 (5), 403-410.

(67) Zhang, J.-M.; Ma, F.; Xu, K.-W. Calculation of the Surface Energy of FCC Metals with Modified Embedded-Atom Method. Appl. Surf. Sci. 2004, 229 (1-4), 34-42.

(68) Chorkendorff, I.; Niemantsverdriet, J. W. Concepts of Modern Catalysis and Kinetics; Wiley-VCH Verlag GmbH: Weinheim, 2003.

(69) Lucci, F. R.; Lawton, T. J.; Pronschinske, A.; Sykes, E. C. H. Atomic Scale Surface Structure of $\mathrm{Pt} / \mathrm{Cu}(111)$ Surface Alloys. J. Phys. Chem. C 2014, 118 (6), 3015-3022.

(70) Fu, Q.; Luo, Y. Catalytic Activity of Single Transition-Metal Atom Doped in $\mathrm{Cu}(111)$ Surface for Heterogeneous Hydrogenation. J. Phys. Chem. C 2013, 117 (28), 14618-14624.

(71) Bach Aaen, A.; Lægsgaard, E.; Ruban, A. .; Stensgaard, I. Submonolayer Growth of Pd on Cu(111) Studied by Scanning Tunneling Microscopy. Surf. Sci. 1998, 408 (1-3), $43-56$.

(72) Yang, K.; Yang, B. Surface Restructuring of Cu-Based Single-Atom Alloy Catalysts under Reaction Conditions: The Essential Role of Adsorbates. Phys. Chem. Chem. Phys. 2017, 19 (27), 18010 18017.

(73) Calle-Vallejo, F.; Tymoczko, J.; Colic, V.; Vu, Q. H.; Pohl, M. D.; Morgenstern, K.; Loffreda, D.; Sautet, P.; Schuhmann, W.; Bandarenka, A. S. Finding Optimal Surface Sites on Heterogeneous Catalysts by Counting Nearest Neighbors. Science (80-. ). 2015, 350 (6257), 185-190. 
Table of Contents Graphic

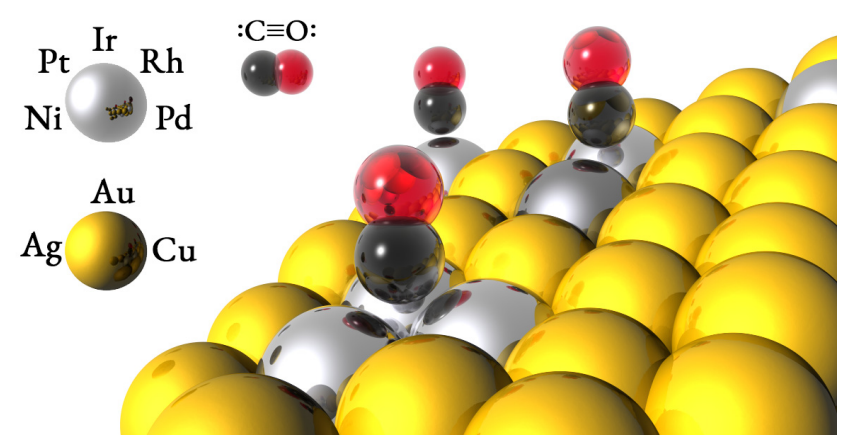




\title{
CO Induced Aggregation and Segregation of Highly Dilute Alloys: A Density Functional Theory Study
}

\author{
Konstantinos G. Papanikolaou, Matthew T. Darby and Michail Stamatakis* \\ Department of Chemical Engineering, University College London, Roberts Building, Torrington Place, \\ London WC1E 7JE, United Kingdom
}

\section{SUPPLEMENTARY MATERIAL}

\section{Choosing the $\mathrm{k}$ points mesh}

To select the Monkhorst-Pack k-point mesh for our calculations, we have performed convergence tests on both (211) and (100) surfaces. In particular, we monitor how the Eads $(\mathrm{CO})$ on the top dopant site of $\mathrm{Pt} / \mathrm{Cu}(100)$ and $\mathrm{Pt} / \mathrm{Cu}(211)$ SAAs is changing with respect to the Monkhorst-Pack k-point mesh (Figure S1). Based on these results, we choose to sample the Brillouin zones of the (211) step and (100) using a $6 \times 5 \times 1$ and a $7 \times 7 \times 1 \mathrm{k}$-point mesh, respectively. These sampling schemes appear to provide very similar $\mathrm{E}_{\text {ads }}(\mathrm{CO})$ to what obtained with highly dense k-point meshes (e.g. $12 \times 12 \times 1$ and $9 \times 7 \times 1$ for (100) and (211) surfaces, respectively) (see Figure S1).
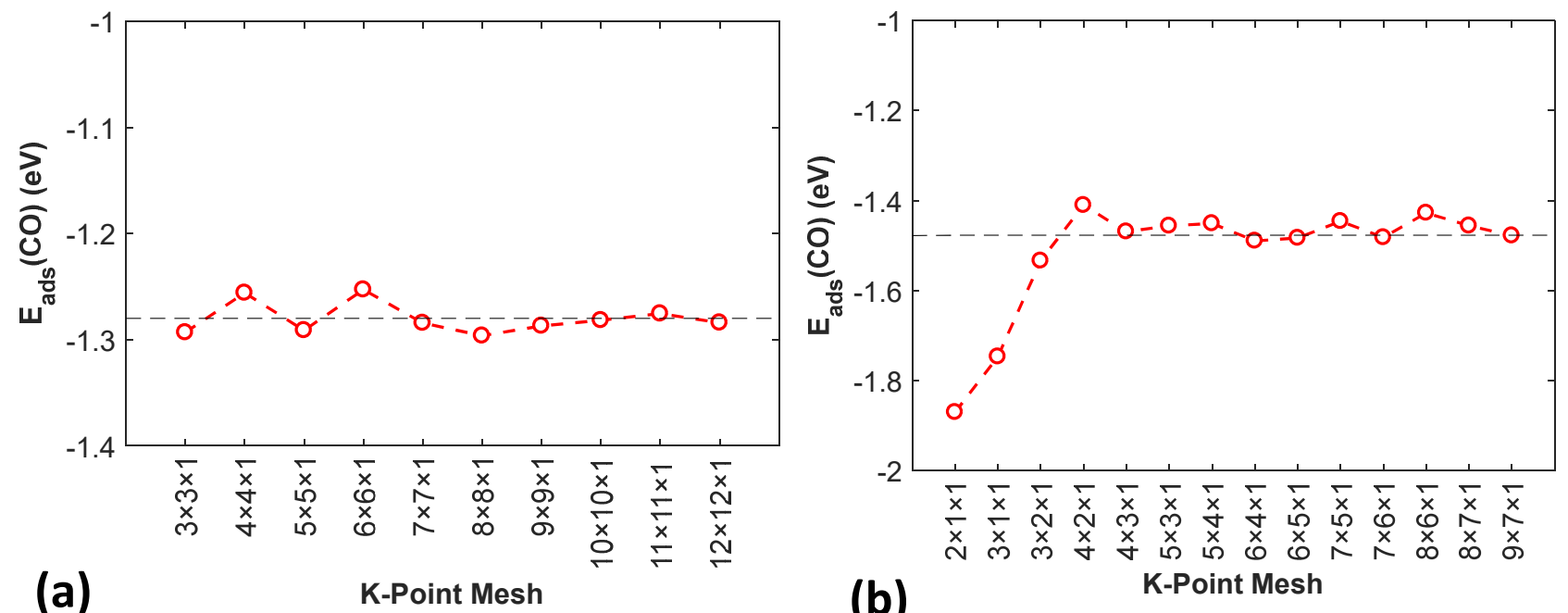

Figure S1. Panels (a) and (b) show the calculated adsorption energies of $\mathrm{CO}$ on $\mathrm{Pt} / \mathrm{Cu}(100)$ and $\mathrm{Pt} / \mathrm{Cu}(211)$ SAAs for various k-point meshes, respectively.

\section{Surface aggregation studies - dopant trimers}

Dopant atoms can aggregate to form trimers, which will likely configurations to occur on highly dilute alloy surfaces. Herein, we consider one dopant trimer configuration on each of the (100) and (211) surfaces. These two trimers are seen in Figure S2, along with the potential adsorption sites, whereon we have calculated $\mathrm{E}_{\text {ads }}(\mathrm{CO})$. As seen, the (211) dimer is composed by two dopant atoms on the edge, plus another one on the (111) terrace next to it. 
We calculate $\Delta E_{a g g}$ for 13 alloys and investigate how these energies may change at different coverage of dopant trimers with CO. Under vacuum conditions, the formation of trimers on the (100) is favoured on the surface of only $\mathrm{Ir} / \mathrm{Cu}$, Ir/Ag alloys (Figure S3 (a)). Similarly, (211) aggregates are stable on the aforementioned alloys, but are also favoured on $\mathrm{Ni} / \mathrm{Ag}, \mathrm{Rh} / \mathrm{Ag}$ and $\mathrm{Rh} / \mathrm{Au}\left(\Delta E_{a g g}<0\right)$ surfaces ((Figure $\mathrm{S} 3$ (a)).
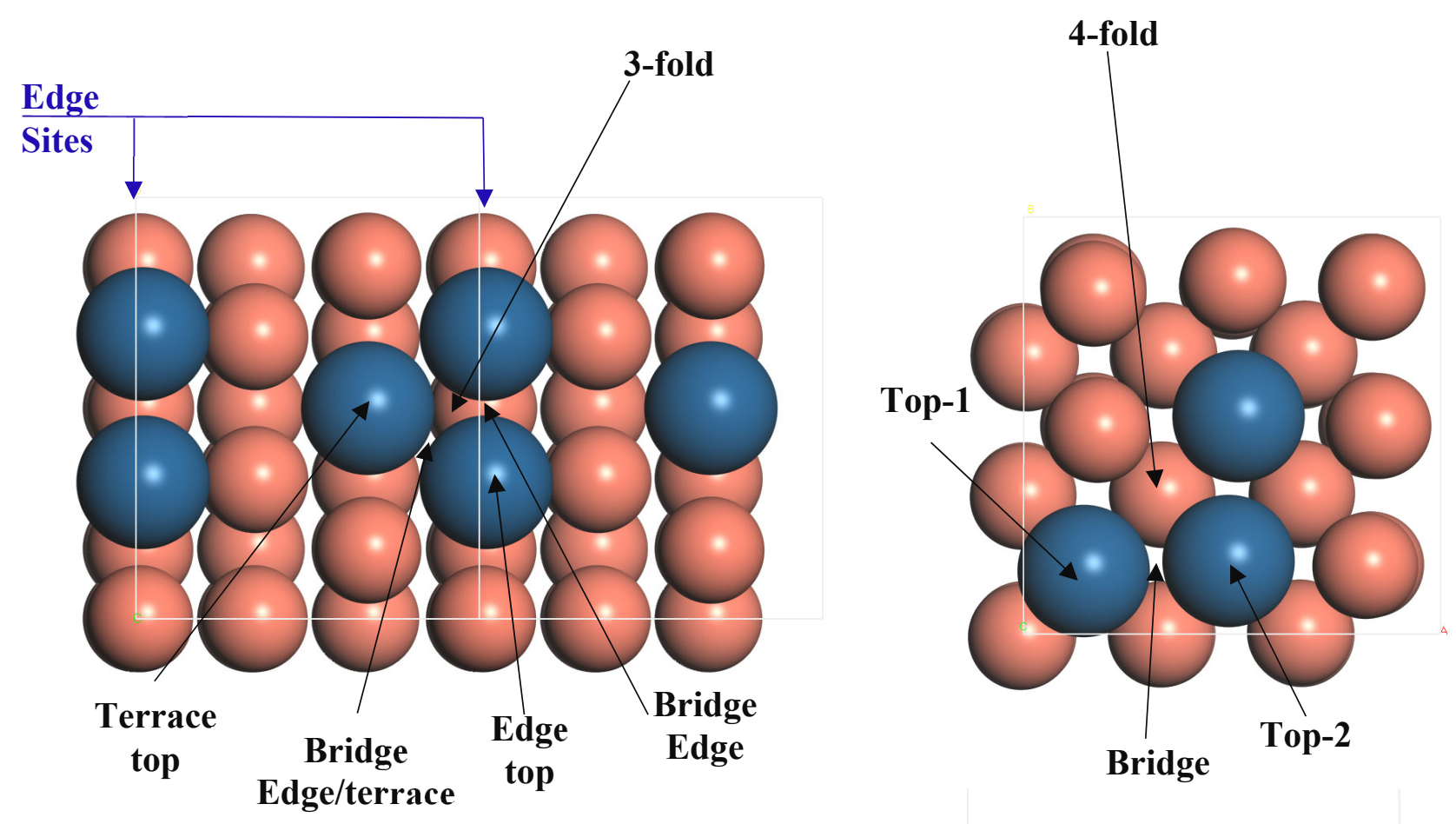

(a)

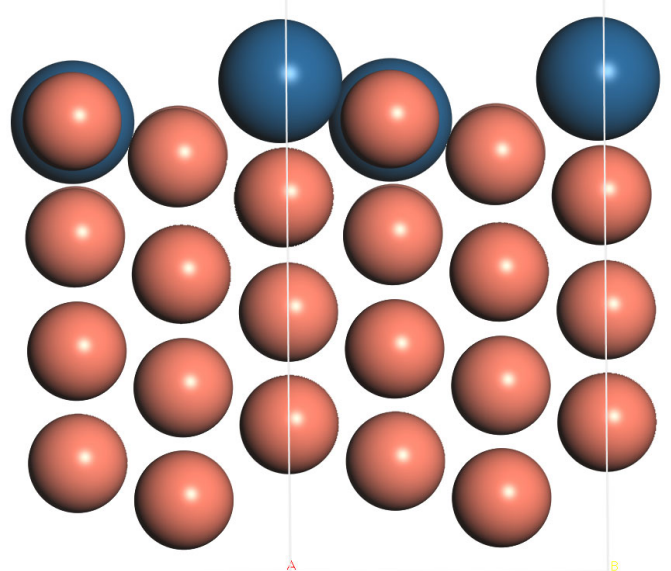

(b)

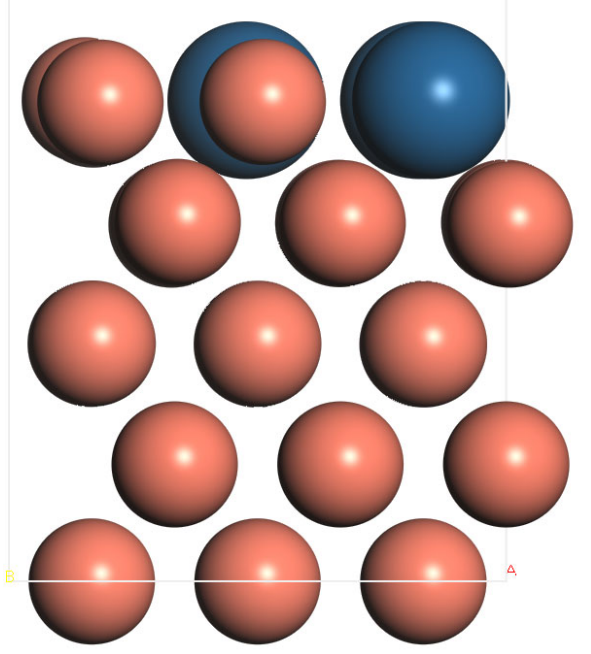

Figure S2. (a) The inset in the first row shows the top view of the (211) slab, where there is a dopant trimer formed (blue spheres). The potential adsorption sites in this configuration are shown with black arrows. The inset in the second row shows the side view of the same slab. (b) The inset in the first row shows the top view of the (100) slab, where there is a dopant trimer formed (blue spheres). The potential adsorption sites in this configuration are shown with black arrows. The inset in the second row shows the side view of the same slab.

At low $\mathrm{P}_{\mathrm{CO}}$, such that there is only one CO adsorbed on the most stable site of (211) and (100) trimers, we induce aggregation in all $\mathrm{Au}$ - and Ag-based alloys, but also on $\mathrm{Ni} / \mathrm{Cu}(100), \mathrm{Ni} / \mathrm{Cu}(211)$ and $\operatorname{Ir} / \mathrm{Cu}(100)$ surfaces. On the other hand, we cannot induce trimer aggregation on $\mathrm{Pd} / \mathrm{Cu}, \mathrm{Pt} / \mathrm{Cu}$ and $\mathrm{Rh} / \mathrm{Cu}(100)$ and (211) surfaces in the presence of a single CO. This was also true for aggregation into dimers (see main text). Finally, 
at $\mathrm{CO}$ dopant fractional coverage of $>0.5$, dopant atom dispersion is promoted in most of the cases (Figure S3 (b) and (c)). The preference for the SAA phase is even more pronounced under full dopant coverage conditions, where there is only a slight propensity for aggregation on the edge of $\operatorname{Ir} / \mathrm{Ag}$ and Ni/Ag $\left(\Delta \mathrm{E}_{a g g}=-\right.$ 0.08 and -0.10 , respectively) (Figure S3 (c))
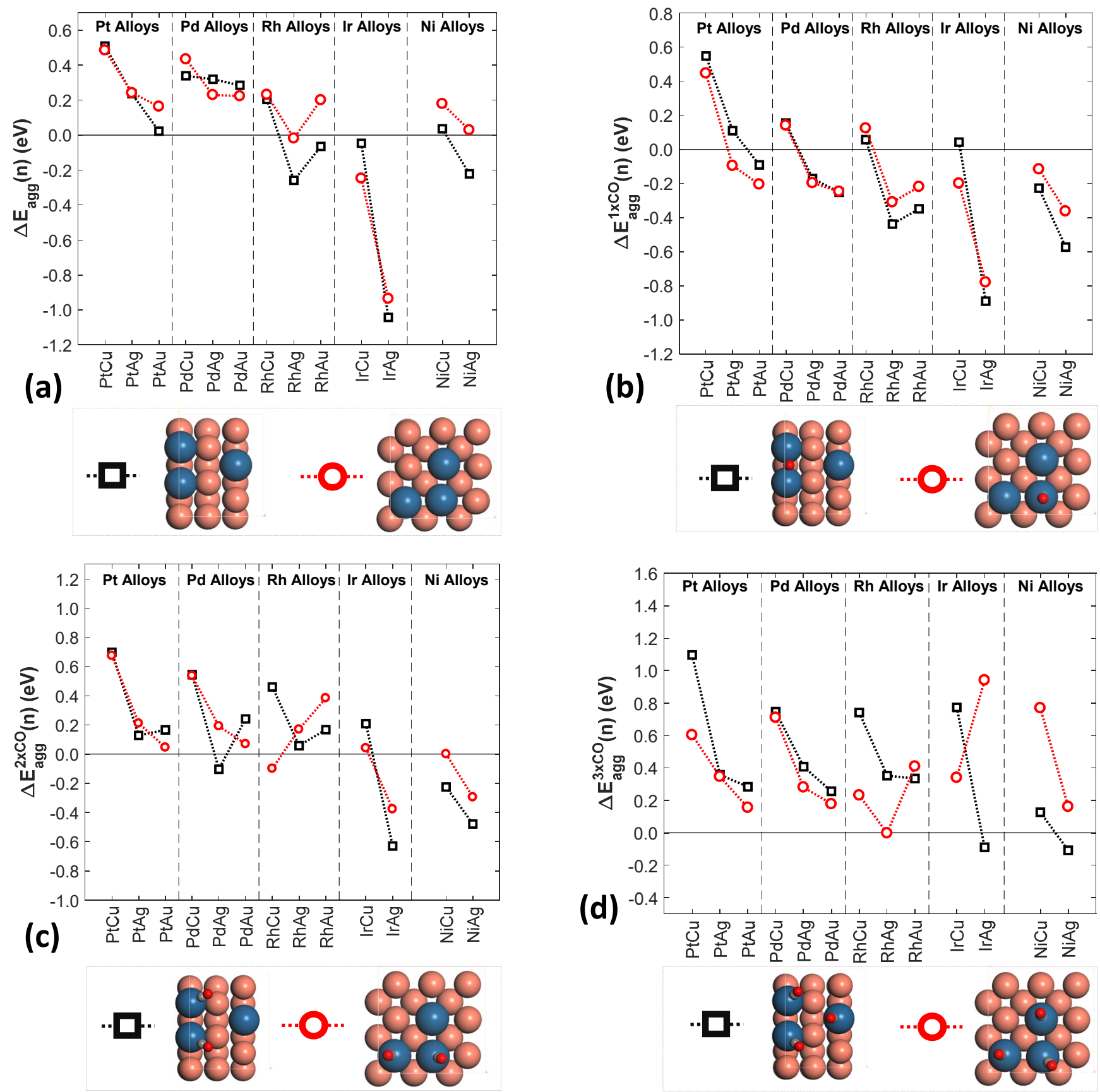

Figure S3. Aggregation energies $\left(\Delta E_{\text {agg }}\right)$ for trimers relative to the SAA phase of Ni, $\mathrm{Pd}, \mathrm{Pt}, \mathrm{Rh}$ and Ir doped into the (100) and (211) surfaces of the group 11 metals with (a) no adsorbed CO molecule; (b) 1 adsorbed CO molecule; (c) 2 adsorbed CO molecules and (d) 3 adsorbed $\mathrm{CO}$ molecules. The legend below each plot, show dimer configurations in the relaxed state; therein carbon, coinage metal, dopant metal and oxygen atoms are represented by grey, orange, blue and red spheres, respectively. 